\title{
Contextual and Developmental Differences in the Neural Architecture of Cognitive Control
}

\author{
(D)Raluca Petrican ${ }^{1}$ and Cheryl L. Grady ${ }^{1,2}$ \\ ${ }^{1}$ Rotman Research Institute, Toronto, Ontario M6A 2E1, Canada, and 2Departments of Psychology and Psychiatry, University of Toronto, Ontario M6A 2E1, \\ Canada
}

Because both development and context impact functional brain architecture, the neural connectivity signature of a cognitive or affective predisposition may similarly vary across different ages and circumstances. To test this hypothesis, we investigated the effects of age and cognitive versus social-affective context on the stable and time-varying neural architecture of inhibition, the putative core cognitive control component, in a subsample $(N=359,22-36$ years, 174 men) of the Human Connectome Project. Among younger individuals, a neural signature of superior inhibition emerged in both stable and dynamic connectivity analyses. Dynamically, a context-free signature emerged as stronger segregation of internal cognition (default mode) and environmentally driven control (salience, cingulo-opercular) systems. A dynamic social-affective contextspecific signature was observed most clearly in the visual system. Stable connectivity analyses revealed both context-free (greater default mode segregation) and context-specific (greater frontoparietal segregation for higher cognitive load; greater attentional and environmentally driven control system segregation for greater reward value) signatures of inhibition. Superior inhibition in more mature adulthood was typified by reduced segregation in the default network with increasing reward value and increased ventral attention but reduced cingulo-opercular and subcortical system segregation with increasing cognitive load. Failure to evidence this neural profile after the age of 30 predicted poorer life functioning. Our results suggest that distinguishable neural mechanisms underlie individual differences in cognitive control during different young adult stages and across tasks, thereby underscoring the importance of better understanding the interplay among dispositional, developmental, and contextual factors in shaping adaptive versus maladaptive patterns of thought and behavior.

Key words: default mode network; functional networks; inhibitory control; motivation; working memory

\section{Significance Statement}

The brain's functional architecture changes across different contexts and life stages. To test whether the neural signature of a trait similarly varies, we investigated cognitive versus social-affective context effects on the stable and time-varying neural architecture of inhibition during a period of neurobehavioral fine-tuning (age 22-36 years). Younger individuals with superior inhibition showed distinguishable context-free and context-specific neural profiles, evidenced in both static and dynamic connectivity analyses. More mature individuals with superior inhibition evidenced only context-specific profiles, revealed in the static connectivity patterns linked to increased reward or cognitive load. Delayed expression of this profile predicted poorer life functioning. Our results underscore the importance of understanding the interplay among dispositional, developmental, and contextual factors in shaping behavior.

\section{Introduction}

A rapidly growing body of research testifies to the importance of the brain's intrinsic functional architecture for optimal adaptation across the lifespan (e.g., Hampson et al., 2006; Church et al.,

\footnotetext{
Received March 10, 2017; revised June 5, 2017; accepted June 29, 2017.

Author contributions: R.P. and C.L.G. designed research; R.P. and C.L.G. performed research; R.P. and C.L.G. contributed unpublished reagents/analytic tools; R.P. and C.L.G. analyzed data; R.P. and C.L.G. wrote the paper.

This work was supported by the Canadian Institutes of Health Research MOP14036 to C.L.G. and the Canada Research Chairs program. Data were provided by the Human Connectome Project, WU-Minn Consortium (Principal Investigators: David Van Essen and Kamil Ugurbil; 1U54MH091657) funded by the 16 NIH Institutes and (enters that support the NIH Blueprint for Neuroscience Research; and by the McDonnell Center for Systems Neuroscience at Washington University. We thank the HCP team for their invaluable contribution in generating and making available the comprehensive HCP neurobehavioral data.

The authors declare no competing financial interests.
}

2009; Li et al., 2009; Van den Heuvel et al., 2009; Fair et al., 2010; Graham et al., 2015; Alavash et al., 2015; Grady et al., 2016). This work raises the possibility that an individual's cognitive or affective characteristics may be associated with stable neural signatures. Nonetheless, there is substantial evidence that the brain's functional architecture undergoes significant changes, both longitudinally as a reflection of development and accumulated behavioral history (e.g., Fair et al., 2007, 2008; Wig et al., 2011; Chan et al., 2014) and cross-sectionally as a function of the various

Correspondence should be addressed to Dr. Raluca Petrican, Rotman Research Institute, 3560 Bathurst Street, Toronto, Ontario M6A 2E1, Canada. E-mail: raluca.petrican@gmail.com. DOI:10.1523/JNEUROSCI.0667-17.2017

Copyright $\odot 2017$ the authors $\quad 0270-6474 / 17 / 377711-16 \$ 15.00 / 0$ 
situational demands faced by an individual (Kitzbichler et al., 2011; Moussa et al., 2011; Shirer et al., 2012; Di et al., 2013; Mennes et al., 2013; Geerligs et al., 2015; Gonzalez-Castillo et al., 2015). Consequently, the brain mechanisms underlying variations in a specific cognitive or affective predisposition may change significantly across the lifespan and across various contexts. Characterization of such changes is important to furthering understanding of the distinct mechanisms through which a specific predisposition impacts behavior in distinct circumstances and life stages.

To address this issue, we examined contextual and developmental effects on the neural architecture of inhibition, the putative core component of cognitive control (Friedman et al., 2008; Miyake and Friedman, 2012), which has been linked to a wealth of "real-life" outcomes (e.g., Joormann and D'Avanzato, 2010; Piguet et al., 2016). There is substantial evidence that the brain architecture supporting cognitive control shows protracted development, which extends into the mid-20s, whereas by the mid-30s individuals start showing subtle signs of poorer cognitive performance (Toga et al., 2006; Giedd and Rapoport, 2010; Andrews-Hanna et al., 2011; Kaller et al., 2012; Ofen et al., 2012; Veroude et al., 2013; Chai et al., 2014; Vink et al., 2014; Bernard et al., 2016; Kleerekooper et al., 2016; Stephanou et al., 2016). Here, we used data from a sample of participants in the Human Connectome Project (HCP) to investigate developmental changes in the neural architecture of cognitive control during the third and fourth decades of life, a period during which fine-tuning of its neurobehavioral mechanisms, as well as subtle forewarning signs of decline are likely to be observed.

Although most existing investigations assume that the functional neural architecture is stable across time, there is accumulating evidence that the brain demonstrates significant temporal fluctuations not only in activity (Garrett et al., 2013), but also in connectivity patterns (Chang and Glover, 2010; Hutchison et al., 2013; Allen et al., 2014). Moreover, the insights provided by such time-varying (i.e., dynamic) functional connectivity patterns reportedly complement and extend those obtained with traditional stable connectivity analyses (Hutchison and Morton, 2015; Marusak et al., 2017).

To investigate situational effects on the neural architecture of inhibition, we focused on two contexts, which involve inhibition, but are nonetheless likely to illuminate distinguishable mechanisms associated with it. One was cognitive and involved a working memory task requiring continual updating of information, a context in which inhibitory control plays a critical role (Gazzaley et al., 2005; Friedman et al., 2008; Rissman et al., 2009). The second involved social and financial rewards derived from a theory-of-mind and a decision-making task (Izuma et al., 2008; Liang et al., 2010), respectively. This context was included because of substantial evidence for a bidirectional relationship between cognitive control, particularly, inhibition, and reward (i.e., cognitive control is instrumental in regulating responses to reward, but reward, in turn, influences cognitive control performance) (Engelmann and Pessoa, 2007; Krawczyk et al., 2007; Watanabe, 2007; Hübner and Schlösser, 2010; Jimura et al., 2010; Berger, 2011; Paschke et al., 2015).

\section{Materials and Methods}

\section{Participants}

The present study included 359 unrelated participants from the HCP, whose data had been released as part of the HCP 900 subjects' data package in December 2015. The 359 participants included in our present report represented the largest number of participants from the HCP 900 subjects' data release who were unrelated to one another and who had completed all the behavioral and fMRI assessments of interest.

The sample included 174 men ( 57 between 22 and 25 years of age, 67 between 26 and 30 years of age, and 50 between 31 and 36 years of age) and 185 women ( 50 between 22 and 25 years of age, 68 between 26 and 30 years of age, and 67 between 31 and 36 years of age). Although age is presented here in the range format, as advocated by the HCP team (for the rationale behind this age reporting strategy in HCP data releases, see Van Essen et al., 2012), all our brain-behavior analyses used participants' actual age in years, as available in the HCP restricted data release.

The majority of participants $(N=301)$ were right-handed. All participants were screened for a history of neurological and psychiatric conditions and use of psychotropic drugs, as well as for physical conditions or bodily implants that may render their participation unsafe. Diagnosis with a mental health disorder and structural abnormalities, as revealed by the MRI structural scans, were also exclusion criteria. Participants provided informed consent in accordance with the HCP research ethics board.

\section{Inhibitory control}

The National Institutes of Health's Toolbox Flanker Inhibitory Control and Attention Test, completed on day 2 of the participants' HCP schedule, gauged participants' ability to focus on a given target stimulus while inhibiting attention to stimuli (arrows, for the present sample) flanking it. The task encompasses two types of trials: congruent (i.e., when the target stimulus is pointing in the same direction as the "flankers") and incongruent (i.e., when the target stimulus is pointing in the opposite direction from the "flankers"). The participants' scores, included in the HCP 900 subjects' data package, were normalized to an average of 100 and SD of 10 (based on the full Toolbox norming sample) and were computed by taking into account both accuracy and reaction time (i.e., for participants with an accuracy rate of $\leq 80 \%$, their total score equals their accuracy score [rescaled to the $0-5$ range], whereas for participants showing accuracy rates $>80 \%$, their total score is an average of their accuracy score, rescaled to the $0-5$ range, and their median speed on the correct incongruent trials also rescaled to the $0-5$ range).

\section{Psychological functioning}

As a measure of psychological functioning, participants completed the Achenbach Adult Self-Report (ASR) for ages 18-59 years (Achenbach, 2009) on the day of their Session 1 fMRI appointment. The ASR contains a total of 123 items, which require participants to rate on a 3 point scale ( 0 , not true; 1 , somewhat or sometimes true; 2 , very true or often true) how well different items described them over the previous 6 months. Raw scores on all ASR Problem Subscales were provided in the HCP 900 subjects' data release, available for download from the ConnectomeDB (https://db.humanconnectome.org). A brief description of the eight problem scales follows next.

Anxious/Depressed Problem Subscale. This subscale assesses both depressive (e.g., "I cry a lot," "I am unhappy, sad, or depressed") and anxiety-related (e.g., "I worry about my future," "I am too fearful or anxious") problems.

Withdrawn Problem Subscale. This subscale gauges problems in interpersonal functioning (e.g., "I don't get along with other people," "I have trouble making or keeping friends").

Somatic Complaints Problem Subscale. This subscale assesses physical problems in the absence of known medical causes (e.g., headaches, nausea, eye problems).

Thought Problem Subscale. This subscale measures obsessive or merely unusual thought patterns (e.g., "I can't get my mind off certain thoughts," "I hear sounds or voices that other people think are not there").

Attention Problem Subscale. This subscale gauges attentional and decision-making difficulties (e.g., "I have trouble concentrating or paying attention for long," "I am not good at details," "I have trouble making decisions," "I have trouble planning for the future").

Aggressive Behavior Problem Subscale. This subscale assesses both participants' explicitly aggressive behaviors (e.g., "I argue a lot," "I am mean to others," "I get in many fights," "I scream or yell a lot"), as well as their emotional stability and reactivity to stressors (e.g., "My moods or feelings change suddenly," "I have a hot temper," "I get upset too easily"). 
Rule Breaking Problem Subscale. This subscale gauges nonaggressive behavior that conflicts with implicit or explicit social rules (e.g., "I lie or cheat," "I steal," "I have trouble keeping a job").

Intrusive Behavior Problem Subscale. This subscale measures nonaggressive, yet socially disruptive behavior (e.g., "I brag," "I show off or clown," "I am louder than others").

\section{fMRI tasks}

Working memory. Participants completed two runs of an $n$-back task, which included as targets four categories of stimuli: faces, places, tools, and body parts. Each run encompassed 8 task blocks ( $27.5 \mathrm{~s}$ each) and 4 fixation blocks ( $15 \mathrm{~s}$ each). The 8 task blocks corresponded to two working memory tasks (Two-back vs Zero-back), with each comprising all four stimulus categories, presented in separate blocks. In the Two-back working memory task, participants had to respond "target" whenever the current stimulus was the same as the one presented two trials before. In the Zero-back working memory task, a stimulus was presented at the beginning of each block and the participants had to respond "target" whenever the respective stimulus was encountered during the block. Each block began with the $2.5 \mathrm{~s}$ presentation of a cue indicating task type and, for the Zero-back task only, target stimulus, followed by 10 trials of $2.5 \mathrm{~s}$ each ( $2 \mathrm{~s}$ stimulus presentation and $500 \mathrm{~ms}$ interstimulus interval) for a total block duration of 27.5 s. Each block contained 2 targets and 2 or 3 nontarget lures (e.g., repeated items in the wrong $n$-back position, either 1-back or 3-back) to ensure that participants are actively drawing on their memory resources to complete the task (for further discussion, see Barch et al., 2013).

Social cognition (theory-of-mind). Participants completed two runs of a task, adapted from Castelli et al. (2000) and Wheatley et al. (2007), in which they were presented with short videos $(20 \mathrm{~s})$ of objects (squares, circles, triangles), either interacting in a purposeful manner or just moving randomly across the screen. After each video, the participants had to decide among three alternative answers: (1) Social Interaction: the video portrayed a social interaction (i.e., an interaction in which the shapes appear to take into account each other's thoughts and emotions); (2) Not Sure (whether the video depicted a social interaction or just random movement); (3) No Interaction: the video showed shapes moving randomly across the screen. Each of the two task runs has 5 video blocks of $23 \mathrm{~s}$ each ( 2 Mental and 3 Random in one run, 3 Mental and 2 Random in the other run) and 5 fixation blocks ( $15 \mathrm{~s}$ each).

Incentive processing. Participants completed two runs of a task, adapted from Delgado et al. (2000), in which they were required to guess the number on a mystery card (represented by a "?") to win or lose money. They were told that potential card numbers ranged from 1 to 9 and were asked to indicate whether they thought the mystery card number was more or $<5$ by pressing one of two buttons on the response box. Feedback is the number on the card (generated by the program, after the participants made their guess, as a function of whether the trial was a reward, loss, or neutral trial) and: (1) a green up arrow with " $\$ 1$ ” for reward trials, (2) a red down arrow next to $-\$ 0.50$ for loss trials; or (3) the number 5 and a gray double headed arrow for neutral trials. The "?" was presented for up to $1.5 \mathrm{~s}$ (if the participant responded before $1.5 \mathrm{~s}$, a fixation cross was displayed for the remaining time), followed by the feedback for $1 \mathrm{~s}$. There was a $1 \mathrm{~s}$ interstimulus interval with a "+" presented on the screen. The task was presented in blocks of 8 trials that were either mostly reward ( 6 reward trials pseudo-randomly interleaved with either 1 neutral and 1 loss trial, 2 neutral trials, or 2 loss trials) or mostly loss (6 loss trials interleaved with either 1 neutral and 1 reward trial, 2 neutral trials, or 2 reward trials). In each of the two runs, there were 2 mostly reward and 2 mostly loss blocks ( $28 \mathrm{~s}$ each), interleaved with 4 fixation blocks ( $15 \mathrm{~s}$ each).

\section{fMRI task data}

Accuracy was at ceiling on the social cognition task, and it was not a relevant measure on the incentive processing task because the sequence of rewards and punishments was preprogrammed. Consequently, for the social-affective context, median reaction times on the high reward (i.e., the reward trials on the incentive processing task and the correctly classified theory-of-mind trials from the social cognition task) and low re- ward trials (i.e., the punishment trials on the incentive processing task and the correctly classified random movement trials from the social cognition task) were used as outcome measures. For the working memory task, we used the accuracy and median reaction time data from the zero- and two-back conditions as behavioral outcomes. For ease of interpretation, the standardized median reaction time scores in both the social-affective and cognitive contexts were multiplied by -1 to be turned into speed scores. Speed scores on the high and low reward value trials were highly intercorrelated (Spearman's rho of $0.70, p<0.0001$ ). Accuracy and speed scores in the two conditions of the working memory task were significantly intercorrelated (Spearman's rho values of 0.53 and 0.65 , respectively, both $p$ values $<0.001$ ). Likewise, within each working memory condition, accuracy and speed were significantly intercorrelated (Spearman's rho of 0.47 and 0.23 , respectively, both $p$ values $<0.001$ ).

\section{fMRI data acquisition}

Images were acquired with a customized Siemens 3T "Connectome Skyra" scanner housed at Washington University in St. Louis (32channel coil). Pulse and respiration were measured during scanning. T1-weighted anatomical scans were acquired with a 3D MP-RAGE sequence $(\mathrm{TR}=2400 \mathrm{~ms}, \mathrm{TE}=2.14 \mathrm{~ms}$, FOV $=224 \mathrm{~mm}, 320 \times 320$ matrix, 256 slices of $0.7 \mathrm{~mm}$ isotropic voxels). The high-resolution structural scan preceded the acquisition of functional scans.

Functional images were acquired with a multiband EPI sequence $\left(\mathrm{TR}=720 \mathrm{~ms}, \mathrm{TE}=33.1 \mathrm{~ms}\right.$, flip angle $=52^{\circ}, \mathrm{FOV}=208 \mathrm{~mm}, 104 \times 90$ matrix, 72 slices of $2 \times 2 \mathrm{~mm}$ in-plane resolution, $2 \mathrm{~mm}$ thick, no gap; multiband acceleration factor $=8$ ). For each task, two runs of equal duration were obtained: one collected with an L-R, and the other, with an $\mathrm{R}-\mathrm{L}$, EPI phase-coding sequence. The length of one task run (in minutes) was as follows: 5:01 (working memory), 3:27 (social cognition), and 3:12 (incentive processing).

Individual L-R and R-L scans exhibit distinct regions of complete signal loss, but it has been verified that the preprocessed datasets are anatomically well aligned with one another, even in areas of complete signal loss (compare S. M. Smith et al., 2013). Because it is only the dropout that differs between the two scan types, it has been recommended that connectivity analyses based on HCP data aggregate the respective metrics from the L-R and R-L resting state scans (compare S. M. Smith et al., 2013). Consequently, in the present report, we concatenated the L-R and R-L runs for each of the three tasks.

\section{fMRI data preprocessing}

The present report used the preprocessed task (i.e., working memory, social cognition, incentive processing) data from the HCP 900 subjects' data release. These data all have been preprocessed with version 3 of the HCP spatial and temporal pipelines (S. M. Smith et al., 2013) (for specification of preprocessing pipeline version, see http://www.humanconnectome.org/data). Spatial preprocessing involved removal of spatial and gradient distortions, correction for participant movement, bias field removal, spatial normalization to the standard MNI- 152 template $(2 \mathrm{~mm}$ isotropic voxels), intensity normalization to a global mean, and masking out of nonbrain voxels. Subsequent temporal preprocessing steps involved weak high-pass temporal filtering with the goal of removing linear trends in the data.

Because motion can significantly impact functional connectivity measures (Power et al., 2012; Van Dijk et al., 2012), we implemented several additional preprocessing steps to address this potential confound. First, after extracting the BOLD time-series from our regions of interest (ROIs, see below), but before computing the ROI-to-ROI correlations, we used the Denoising step in the CONN toolbox (version 16b) (WhitfieldGabrieli and Nieto-Castanon, 2012) to apply further physiological and rigid motion corrections. Specifically, linear regression was used to remove from the BOLD time-series of each ROI the BOLD time-series of the voxels within the MNI-152 white matter and CSF masks, respectively (i.e., the default CONN option of five CompCor-extracted principal components for each) (Behzadi et al., 2007), the 6 realignment parameters and their first-order temporal derivatives (compare Cole et al., 2014), as well as the main task condition effects, obtained by convolving a boxcar task design function with the hemodynamic response function, 
and their first-order temporal derivative. Removal of the main task condition effects is consistent with extant theory and practice aimed at disentangling task-related functional connectivity from task-evoked coactivation effects (Friston et al., 1997; Vatansever et al., 2015). Finally, the residual BOLD time-series were bandpass filtered $(0.008 \mathrm{~Hz}<\mathrm{f}<0.09 \mathrm{~Hz})$, linearly detrended, and despiked (all three are default CONN denoising steps).

Second, because even after the aforementioned corrections, some of our network-level functional connectivity indices still displayed a number of statistically significant correlations with the average relative (i.e., volume-to-volume) displacement per participant (i.e., FD), a widely used motion metric (Power et al., 2012, 2015; Satterthwaite et al., 2013), we applied a final correction at the group level. Specifically, before conducting our main analyses, for each condition, we regressed the average relative displacement per participant from each of his or her measures of network connectivity (see below for a description of the specific indices).

\section{fMRI data analysis}

To characterize contextual and individual difference effects on neural architecture, we conducted both dynamic and stable functional connectivity analyses. The purpose of the dynamic connectivity analyses was to shed light on the time-varying functional interactions that were associated with age and individual differences in inhibitory control and that took place over the entire duration of the cognitive or the social-affective task (i.e., not tied to any specific condition within the task run). The purpose of the stable connectivity analyses was to characterize the age and inhibition-linked functional connectivity patterns that typified superior behavioral performance in specific conditions within each of these two contexts (i.e., high vs low cognitive load or reward value).

ROI time-series. A total of 229 nodes for 10 networks (i.e., default $[\mathrm{DMN}]$, frontoparietal $[\mathrm{FPC}]$, cingulo-opercular $[\mathrm{CON}]$, salience $[\mathrm{SAL}]$, dorsal attention $[\mathrm{DAN}]$, ventral attention $[\mathrm{VAN}]$, somatomotor $[\mathrm{SM}]$, subcortical [SUB], auditory [AUD], and visual [VIS]) were defined for each participant as spherical ROIs (radius $5 \mathrm{~mm}$ ) centered on the coordinates of the regions reported by Power et al. (2011) and assigned network labels corresponding to the graph analyses from this earlier article. The ROIs were created in FSL (S. M. Smith et al., 2004), using its standard $2 \mathrm{~mm}$ isotropic space, with each ROI containing 81 voxels. These template space dimensions were selected because they yielded the most adequate spatial representation of the Power atlas. The reslicing of the functional data into the $2 \mathrm{~mm}$ MNI space was performed in CONN during the Set-up stage.

For each participant, we used the CONN toolbox to compute pairwise Pearson's correlations among the time-series of all 229 ROIs during each scrutinized condition. Pearson's $r$ has been widely used as a metric of functional coupling in stable and dynamic connectivity studies alike (e.g., Power et al., 2011, 2012; Zalesky et al., 2014; Vatansever et al., 2015; Chen et al., 2016; Chan et al., 2017), most likely due to the ease of mapping its interpretation onto the concept of functional connectivity (i.e., Pearson's $r$ reflects the extent to which change in one variable is associated with a proportional change in another variable). One caveat is that Pearson's $r$ is influenced by outliers, which, in the context of functional connectivity analyses (i.e., outlier scans), arise mostly due to participant motion and physiological noise. This is why, as discussed in fMRI data analysis, we went to great lengths to reduce the influence of potential outlier scans (via despiking) and correct for physiological and motion-related artifacts, both on a within-participant level (via CompCor and regression of the six motion parameters and their first-order temporal derivatives) and at the group level (by regressing out each participant's summary motion statistic from each of his or her stable and dynamic connectivity indices described below). An inspection of each subject's histogram of voxel-to-voxel connectivity values for each scrutinized condition revealed a normal distribution, approximately centered around zero, which would suggest reduced contamination from physiological and motion-related confounds (compare Whietfield-Gabrieli and Castanon, 2012).

Thus, for the stable connectivity analyses, we computed six correlation matrices encompassing the pairwise correlations among the 229 ROIs in each condition of interest: socially suggestive movement, random move- ment, financial gains, financial losses, and zero-back and two-back working memory. For dynamic connectivity analyses, the correlation matrices were computed for each relevant time window (for details, see below). For both stable and dynamic connectivity analyses, the pairwise correlations among all the ROIs were expressed as Fisher's $z$ scores.

Consistent with existing practices aimed at maximizing interpretability of results in neural network studies of individual or group differences (e.g., sex or age) (Betzel et al., 2014; Satterthwaite et al., 2015), we used both positive and negative $z$ scores to compute the indices of interest for both dynamic and stable functional connectivity analyses. We reasoned that such an approach would be particularly well justified in our present case because global signal regression, the main determinant of spurious negative connectivity values, was not part of our preprocessing pipeline (for further discussion on the validity of the negative correlations obtained with the CONN toolbox, see Whitfield-Gabrieli and NietoCastanon, 2012).

Dynamic connectivity: sliding window analyses. Pairwise dynamic coupling among the 229 ROIs was estimated in CONN using a sliding window of $20 \mathrm{~s}$ in length $(\sim 28$ volumes $)$ with one TR gap in-between windows and a "hanning weighting" (i.e., greater weight to the scans in the middle of the window relative to the ones at the periphery) applied to all the time points within a window. The social-affective task included 156 windows in total. In its entirety, the working memory task comprised 192 windows. To ensure that any observed differences between the two task contexts were not due to time-series length, we eliminated 36 windows from the working memory task (nine from each condition [zeroback vs two-back] within each run [LR vs RL]). Although we favor this analytic strategy for the main analyses herein described, we nonetheless verified that all the reported effects hold if tests are performed on all the windows from the working memory task.

Network-level analyses. Apart from the stable network-specific segregation indices, all the other network-level metrics were computed using the Brain Connectivity Toolbox (BCT) (Rubinov and Sporns, 2010). Before conducting our brain-behavior analyses, average FD per participant was regressed out from each of the network metrics described below.

Whole-brain modularity. Rather than being computed directly, modularity, that is, the degree to which a network could be divided into well-delineated and nonoverlapping communities, is estimated using optimization algorithms, which sacrifice some degree of accuracy for processing speed (Rubinov and Sporns, 2010). Here, for both dynamic and stable connectivity analyses, whole-brain modularity was estimated using a Louvain community detection algorithm implemented in the $\mathrm{BCT}$. This algorithm partitions a network into nonoverlapping groups of nodes with the goal of maximizing an objective modularity $Q$ function (Rubinov and Sporns, 2011; Betzel and Bassett, 2016). For signed networks, such as the ones investigated in our study, optimization of the Q function can be achieved by either placing equal weight on maximizing positive within-module connections and minimizing negative withinmodule connections or by putting a premium on maximizing positive connections, which have been argued to be of greater biological significance (Rubinov and Sporns, 2011). The first form of the modularity function Q (Traag and Bruggeman, 2009) is written as follows:

$$
Q=\frac{1}{v^{+}+v^{-}} \sum_{i j}\left[\left(w_{i j}^{+}-\gamma e_{i j}^{+}\right)-\left(w_{i j}^{-}-\gamma e_{i j}^{-}\right)\right] \delta_{M_{i} M_{j}}
$$

where $\delta_{M_{i} M_{j}}=1$ if nodes $i$ and $j$ are in the same module and $\delta_{M_{i} M_{j}}=0$ otherwise; $v^{+}$and $v^{-}$constitute the sum of all positive $\left(w^{+}\right)$and all negative $\left(w^{-}\right)$weights in the network, respectively; $w_{i j}^{ \pm}$represents the actual within-module positive or negative connection weights with $w^{ \pm}$ $\in(0,1] ; \gamma$ is a resolution parameter determining the size of the identified modules; $e_{i j}^{+}$is the within-module connection strength expected by chance and defined, for each node-to-node $(i, j)$ connection as $e_{i j}^{ \pm}=\frac{s_{i}^{ \pm} s_{j}^{ \pm}}{v^{ \pm}}$, with $s_{i}^{ \pm}$and $s_{j}^{ \pm}$being the sum of all positive or all negative connection weights of node $i$ and $j$, respectively, whereas $v^{ \pm}$is the sum of all positive or all negative connection weights in the network.

The adapted modularity function $\mathrm{Q}^{*}$, proposed by Rubinov and Sporns (2011), is written as follows: 


$$
Q^{*}=\frac{1}{v^{+}} \sum_{i j}\left(w_{i j}^{+}-\gamma e_{i j}^{+}\right) \delta_{M_{i} M_{j}}-\frac{1}{v^{+}+v^{-}} \sum_{i j}\left(w_{i j}^{-}-\gamma e_{i j}^{-}\right) \delta_{M_{i} M_{j}}
$$

In the above formulation, the contribution of positive weights to $\mathrm{Q}$ is not affected by the presence of negative weights in the network, whereas the contribution of negative weights to $\mathrm{Q}$ decreases with an increase in positive weights.

Both above formulations of the $\mathrm{Q}$ function have been used in prior studies of stable and dynamic connectivity (e.g., Bassett et al., 2011; Chen et al., 2016). Thus, particularly because it remains unclear the extent to which different preprocessing strategies may impact the boundary between positive and negative connection weights, we tested the robustness of our results across estimates of community structure obtained with both $\mathrm{Q}$ and $\mathrm{Q}^{*}$.

The value of the resolution parameter $\gamma$ is a second factor that may affect estimates of community structure obtained with a Louvain community detection algorithm. Consequently, following recent recommendations in the literature (e.g., Betzel and Bassett, 2016), we tested the robustness of our results across three critical values of $\gamma: 1$ (the default value), 0 (a value that favors detection of larger modules), and 2 (a value that favors detection of smaller modules) (Rubinov and Sporns, 2010). Because we did not have any specific hypotheses regarding community size and the delineation of negative from positive weights may still partly depend on preprocessing strategies, for our main analyses, we present the results based on the modularity (applicable to both stable and dynamic connectivity) and system segregation (applicable to dynamic connectivity only) estimates aggregated across the three values of the gamma parameter and two types of negative weight treatment (i.e., symmetrical vs asymmetrical). Nonetheless, in Tables 2, 4, and 6, we present the results of analyses using estimates from each of the six combinations of gamma values and negative weight treatment, to provide a sense of the robustness of our findings against variations in the settings of the community detection algorithm.

It has been shown that the modularity function $\mathrm{Q}$ (in its various forms) may show extreme degeneracy, which means that the maximal modularity partition is "hidden" among a relatively large number of "near-perfect" modularity partitions, which are nonetheless structurally dissimilar from one another (Good et al., 2010). To address the fact that the optimization landscape is characterized by the existence of this plateau of high modularity partitions, we followed existing practices in the literature (compare Braun et al., 2015; Chen et al., 2016). Thus, for both dynamic and stable connectivity analyses, the Louvain algorithm was initiated 100 times. Subsequently, to compute the whole-brain and network-specific dynamic and stable modularity or segregation indices described below, we averaged the relevant metrics over all 100 iterations.

Dynamic whole-brain modularity. Following the 100 iterations of the community detection algorithm, run for each of the six gamma valuenegative weight combinations in each of the 156 windows from the working memory or the social-affective task, we obtained, for each participant, 12 matrices containing each node's assignment to a community across the 15,600 whole-brain partitions (number of partitions $=$ number of windows [156] $\times$ number of algorithm iterations [100]), estimated for each of the six gamma value-negative weight combinations in each of the two task contexts. Subsequently, we used the BCT to compute an agreement matrix for each participant in each of the six gamma value-negative weight combinations corresponding to each of the two task contexts. Each entry in this matrix contains the number of times that a given ROI pair was assigned to the same community across the 100 iterations of the modularity algorithm in each relevant sliding window and gammanegative weight treatment combination. Using the BCT, each participant's agreement matrix was rescaled, so that all matrix entries fell within the $[0,1]$ interval. Hence, each entry in this rescaled matrix reflected the percentage of actual interactions between two ROIs from all the possible interactions that they could have had (15,600 within each of the two task contexts in each of the six gamma-negative weight treatment combination). To reach a consensus clustering across all the windows within each of the two task contexts, these rescaled agreement matrices, separately for each gamma-negative weight treatment combination, were subjected to an additional modularity analysis with 100 iterations (compare Lancichinetti and Fortunato, 2012; Bassett et al., 2013). The resulting whole-brain modularity Q scores were averaged across the 100 repetitions and all six gamma-negative weight treatment combinations and used as indices of "spatiotemporal modularity." Higher scores typified those brains whose nodes showed consistent preference in their interactions (i.e., they consistently interacted with some nodes and not with others) across the whole duration of the working memory or the social-affective task. Thus, for any given window, a node's lack of preference in its interactions would have resulted in variable community assignments across the 100 iterations of the Louvain algorithm within each window. Likewise, a node's lack of consistency in its preference for certain interactions would have resulted in variable community assignments across the different task-relevant windows. Both a node's lack of preference and lack of consistency would have resulted in less differentiated patterns of interactions with the remaining nodes and, thus, lower spatiotemporal modularity scores.

There are alternative strategies for estimating modularity and identifying a consensus clustering based on dynamic connectivity patterns. For example, multilayer modularity algorithms allow examination of community dynamics at different time scales (see Mucha et al., 2010; Bassett et al., 2011; Braun et al., 2015). Nonetheless, such algorithms also require estimation of additional free parameters (e.g., the temporal coupling parameter between two adjacent temporal windows), which, in the context of the present study, may have acted as a potential cofound when comparing static and dynamic connectivity results.

Stable whole-brain modularity. For each of the six experimental conditions (socially suggestive movement, random movement, financial gains, financial losses, zero-back, two-back), a spatial modularity Q score was computed by averaging across the relevant $\mathrm{Q}$ scores resulting from the 100 iterations of the community detection algorithm run in each condition and across all six gamma-negative weight treatment combinations.

\section{Network-specific segregation}

Dynamic network segregation. In the context of dynamic connectivity analyses, assignment to the same community within a sliding window is interpreted as reflecting a functional interaction (e.g., compare Braun et al., 2015; Chen et al., 2016). As described above, a participant's agreement matrix contained the number of times that a pair of ROIs interacted across the 100 iterations of the Louvain algorithm in all the task-relevant windows (156 within each of the two task contexts) and in each of the six gamma-negative weight treatment combinations. Based on published network labels (Power et al., 2011), we used each participant's agreement matrix to compute for each network a measure of spatiotemporal segregation, reflecting the tendency of a network's nodes to interact with one another over time rather than with nodes from other networks. The spatiotemporal segregation formula read as follows:

$$
\text { Spatiotemporal system segregation }=\frac{\overline{i_{\text {within }}}}{\overline{i_{\text {between }}}}
$$

where $i_{\text {within }}=$ the average number of interactions among all the nodes within a network and $i_{\text {between }}=$ the average number of interactions between nodes in one network and nodes in all the remaining networks. For the main analyses, for each of the 10 systems from Power et al. (2011), we averaged the spatiotemporal segregation estimates obtained across the six gamma value-negative weight treatment combinations.

Stable network segregation. Based on published network labels (Power et al., 2011), the relevant $z$ scores, obtained with the CONN toolbox for each of the six experimental conditions (as described above), were averaged to create indices of within-network (e.g., the average correlation among all the DMN ROIs) and between-network (e.g., the average correlation of all the DMN ROIs with the ROIs from all remaining networks) connectivity measures. To compare relative changes in within- versus between-network connectivity as a function of cognitive load or reward value, we created an index of spatial segregation written as follows:

$$
\text { Spatial system segregation }=\frac{\overline{c_{\text {within }}}}{\overline{c_{\text {between }}}}
$$




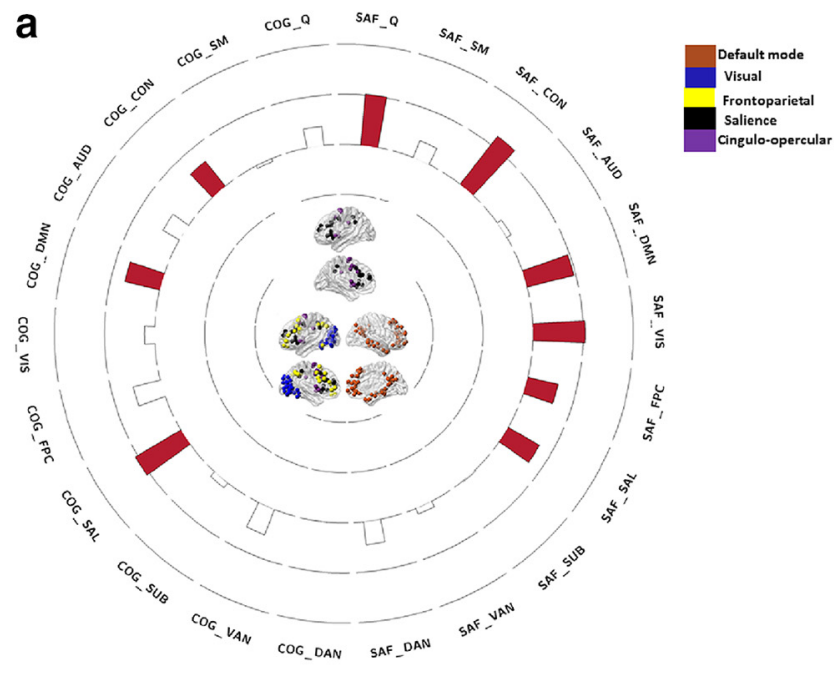

b

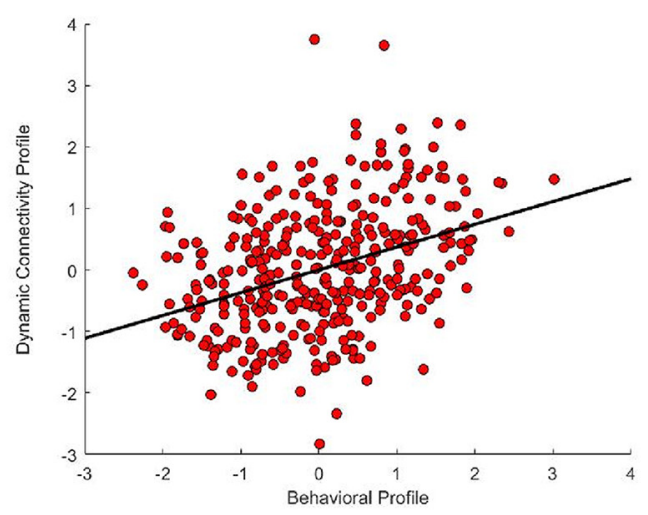

Figure 1. $\quad \boldsymbol{a}$, The loadings of the brain variables from CCA 1 on their corresponding canonical variate. $\boldsymbol{b}$, Scatter plots describing the linear association between the brain and the behavioral (i.e., age and inhibitory control) canonical variates. $\boldsymbol{a}, \mathrm{COG}_{-}$, Working memory context; $\mathrm{SAF}_{-}$, social-affective context; $Q$, whole-brain modularity metric. $\boldsymbol{a}$, Networks with significant loadings on the respective brain variate are represented in the middle of the circular plot, separately for the cognitive (on the left side) versus the social-affective (on the right side) context. Bars in red represent positive loadings of a brain variable on its variate. In the circular plot, the outermost ring represents a canonical loading of 1.0 and the second ring (from the outside) represents a canonical loading of 0.50 . Complementarily, the innermost ring represents a canonical loading of -1.0 , whereas the second ring from the center of the circular plot represents a canonical loading of -0.50 . The networks presented in Figures 1 and 2 were visualized with the BrainNet Viewer (Xia et al., 2013).

where $c_{\text {within }}=$ the average connection strength among all the nodes within a network to which a constant ("1") has been added to render it positive and $\mathrm{c}_{\text {between }}=$ the average connection strength between nodes in one network and nodes in all the remaining networks to which the same constant (" 1 ") has been added to render it positive.

To investigate potential links between individual differences in inhibitory control and stable neural architecture across the two task contexts (social-affective vs cognitive), we subsequently created two sets of residual connectivity scores. The first set consisted of cognitive load-specific functional connectivity measures, computed by regressing out from each two-back connectivity index the corresponding connectivity index value associated with the zero-back working memory condition as a control for the specific demands associated with the working memory task and global variations in functional architecture. Following a similar rationale, the second set, which comprised indices of functional connectivity evoked by high reward value stimuli, was computed by averaging the standardized residual connectivity values specific to the Gain condition (after regressing out the connectivity values corresponding to the Loss
Table 1. CCA 1: dynamic functional connectivity patterns linked to superior inhibitory control during earlier adulthood ${ }^{a}$

\begin{tabular}{|c|c|c|}
\hline Variable & $\begin{array}{l}\text { Canonical } \\
\text { loadings }\end{array}$ & $\begin{array}{l}\text { Standardized } \\
\text { coefficients }\end{array}$ \\
\hline \multicolumn{3}{|l|}{ Brain LV } \\
\hline \multicolumn{3}{|l|}{ Social-affective } \\
\hline Somatomotor & 0.18 & 0.08 \\
\hline Cingulo-opercular & $0.61^{b}$ & 0.46 \\
\hline Auditory & 0.05 & -0.17 \\
\hline Default mode & $0.48^{b}$ & 0.11 \\
\hline Visual & $0.52^{b}$ & 0.34 \\
\hline Frontoparietal & $0.31^{b}$ & 0.02 \\
\hline Salience & $0.36^{b}$ & 0.13 \\
\hline Subcortical & 0.01 & -0.10 \\
\hline Ventral attention & 0.06 & 0.01 \\
\hline Dorsal attention & 0.23 & 0.13 \\
\hline Whole-brain spatiotemporal modularity & $0.51^{b}$ & 0.03 \\
\hline \multicolumn{3}{|l|}{ Cognitive } \\
\hline Somatomotor & -0.03 & -0.18 \\
\hline Cingulo-opercular & $0.32^{b}$ & 0.09 \\
\hline Auditory & 0.19 & 0.12 \\
\hline Default mode & $0.36^{b}$ & 0.15 \\
\hline Visual & 0.10 & -0.08 \\
\hline Frontoparietal & 0.28 & 0.18 \\
\hline Salience & $0.53^{b}$ & 0.46 \\
\hline Subcortical & 0.06 & 0.00 \\
\hline Ventral attention & 0.27 & 0.16 \\
\hline Dorsal attention & 0.00 & -0.20 \\
\hline Whole-brain spatiotemporal & 0.19 & -0.24 \\
\hline \multicolumn{3}{|l|}{ Behavioral LV } \\
\hline Age & $-0.80^{b}$ & -0.75 \\
\hline Inhibitory control & $0.67^{b}$ & 0.60 \\
\hline modularity & & \\
\hline
\end{tabular}

${ }^{a} \mathrm{LV}$, Latent variable.

${ }^{b}$ Canonical loadings with absolute values $>0.30$

condition) of the incentive processing task and the Mental condition (after regressing out the connectivity values corresponding to the Random condition) of the social cognition task.

\section{Brain-behavior analyses}

Canonical correlation analysis (CCA). To identify the relationship of dynamic or stable functional connectivity patterns with age and behavior, we used CCA (Hotelling, 1936). CCA is a multivariate technique, which seeks maximal correlations between two sets of variables by creating linear combinations (i.e., canonical variates) from the variables within each set. Recently, CCA has been successfully used to investigate brainbehavior relationships in large datasets (for an analytic approach similar to ours, see Tsvetanov et al., 2016; for a somewhat different framework, see S. M. Smith et al., 2015). CCA was implemented using the CANCORR module from SPSS 24.0.

To describe the relationship between the behavioral or brain variables and their corresponding variates (i.e., latent factors), we include two types of indicators, specifically, canonical loadings and standardized coefficients. Canonical loadings reflect the raw correlation between a brain or behavioral variable and its corresponding variate. Standardized coefficients represent the partial correlation between a brain or behavioral variable and its corresponding variate, after controlling for the effect of the remaining brain or behavioral variables in the respective analysis.

To obtain reliable estimates of canonical loadings, CCA requires a sample size at least 10 times the number of variables in the analysis (Hair et al., 1998). Our sample size for all tests exceeded this criterion because we had samples $\sim 14$ times the number of variables in the analysis. Because canonical loadings are homologous to factor loadings, it has been recommended that they be subjected to similar criteria for significance (Hair et al., 1998). Given our sample size and existing guidelines regarding sample size requirements for significant factor loadings (Hair et al., 1998), we regarded as significant a canonical loading of at least 0.30 . 
Table 2. Control analyses for CCA 1: canonical correlation coefficients and loadings for the analyses using connectivity indices obtained with alternate community detection parameters (gamma resolution factor, treatment of negative weights) $)^{a}$

\begin{tabular}{|c|c|c|c|c|c|c|}
\hline Variable & $\begin{array}{l}\mathrm{A} / 0 \\
(r=0.37)^{*}\end{array}$ & $\begin{array}{l}\mathrm{A} / 1 \\
(r=0.38)^{*}\end{array}$ & $\begin{array}{l}\mathrm{A} / 2 \\
(r=0.37)^{*}\end{array}$ & $\begin{array}{l}S / 0 \\
(r=0.37)^{*}\end{array}$ & $\begin{array}{l}S / 1 \\
(r=0.38)^{*}\end{array}$ & $\begin{array}{l}S / 2 \\
(r=0.36)^{* *}\end{array}$ \\
\hline \multicolumn{7}{|l|}{ Brain LV } \\
\hline \multicolumn{7}{|l|}{ Social-affective } \\
\hline Somatomotor & 0.19 & 0.21 & 0.28 & 0.22 & 0.16 & 0.23 \\
\hline Cingulo-opercular & $0.69^{b}$ & $0.57^{b}$ & $0.44^{b}$ & $0.70^{b}$ & $0.57^{b}$ & $0.46^{b}$ \\
\hline Auditory & -0.03 & 0.05 & 0.17 & 0.09 & 0.01 & 0.09 \\
\hline Default mode & $0.41^{b}$ & $0.46^{b}$ & $0.49^{b}$ & $0.42^{b}$ & $0.42^{b}$ & $0.53^{b}$ \\
\hline Visual & $0.30^{b}$ & $0.53^{b}$ & $0.59^{b}$ & $0.30^{b}$ & $0.52^{b}$ & $0.59^{b}$ \\
\hline Frontoparietal & $0.22^{b}$ & $0.32^{b}$ & $0.41^{b}$ & $0.24^{b}$ & $0.29^{b}$ & $0.43^{b}$ \\
\hline Salience & $0.32^{b}$ & $0.32^{b}$ & $0.42^{b}$ & $0.30^{b}$ & $0.31^{b}$ & $0.43^{b}$ \\
\hline Subcortical & 0.12 & -0.03 & 0.19 & 0.05 & -0.07 & 0.07 \\
\hline Ventral attention & 0.00 & 0.08 & 0.00 & -0.02 & 0.08 & -0.02 \\
\hline Dorsal attention & 0.29 & 0.24 & 0.18 & 0.30 & 0.22 & 0.24 \\
\hline Whole-brain spatiotemporal modularity & $0.49^{b}$ & $0.47^{b}$ & $0.63^{b}$ & $0.53^{b}$ & $0.44^{b}$ & $0.60^{b}$ \\
\hline \multicolumn{7}{|l|}{ Cognitive } \\
\hline Somatomotor & 0.02 & -0.06 & 0.22 & 0.06 & -0.12 & 0.15 \\
\hline Cingulo-opercular & $0.31^{b}$ & $0.30^{b}$ & $0.43^{b}$ & $0.31^{b}$ & $0.25^{b}$ & $0.34^{b}$ \\
\hline Auditory & 0.16 & 0.21 & 0.14 & 0.20 & 0.18 & 0.17 \\
\hline Default mode & $0.39^{b}$ & $0.34^{b}$ & $0.24^{b}$ & $0.44^{b}$ & $0.31^{b}$ & $0.29^{b}$ \\
\hline Visual & -0.05 & 0.09 & 0.27 & -0.02 & 0.06 & 0.21 \\
\hline Frontoparietal & 0.31 & 0.27 & 0.35 & 0.31 & 0.24 & 0.32 \\
\hline Salience & $0.43^{b}$ & $0.51^{b}$ & $0.59^{b}$ & $0.41^{b}$ & $0.48^{b}$ & $0.62^{b}$ \\
\hline Subcortical & 0.23 & 0.05 & -0.01 & 0.24 & 0.01 & -0.06 \\
\hline Ventral attention & 0.31 & 0.24 & 0.18 & 0.33 & 0.23 & 0.18 \\
\hline Dorsal attention & 0.03 & -0.06 & 0.30 & -0.01 & -0.10 & 0.17 \\
\hline Whole-brain spatiotemporal modularity & 0.28 & 0.11 & 0.38 & 0.30 & 0.09 & 0.30 \\
\hline \multicolumn{7}{|l|}{ Behavioral LV } \\
\hline Age & $-0.88^{b}$ & $-0.77^{b}$ & $-0.99^{b}$ & $-0.90^{b}$ & $-0.72^{b}$ & $-0.95^{b}$ \\
\hline Inhibitory control & $0.55^{b}$ & $0.70^{b}$ & $0.26^{b}$ & $0.51^{b}$ & $0.76^{b}$ & $0.40^{b}$ \\
\hline
\end{tabular}

${ }^{a} \mathrm{LV}$, Latent variable; $\mathrm{A} / 0$, asymmetrical treatment of negative weights/gamma value of $0 ; \mathrm{A} / 1$, asymmetrical treatment of negative weights/gamma value of $1 ; \mathrm{A} / 2$, asymmetrical treatment of negative weights/gamma value of 2; S/0, symmetrical treatment of negative weights/gamma value of $0 ; S / 1$, symmetrical treatment of negative weights/gamma value of $1 ; S / 2$, symmetrical treatment of negative weights/gamma value of 2 .

${ }^{b}$ Variables evidencing canonical loadings with absolute values $>0.30$ in our aggregate condition.

${ }^{*} p<0.0001,{ }^{* *} p<0.005$.

Hierarchical linear modeling (HLM) analyses. To probe the link between the life-functioning (i.e., ASR) variables and the brain connectivity patterns, linked to age and inhibition in the social-affective versus the cognitive context, we used HLM analysis (HLM 7.01) (Raudenbush et al., 2013) with robust SE estimates (Raudenbush and Bryk, 2002), an appropriate choice for the present study, which included a relatively large number of cases.

Univariate and multivariate outliers. Univariate and multivariate outliers can adversely impact data normality and, thus, have the potential to bias the results of canonical correlation analyses (Sherry and Henson, 2005). Nonetheless, because all the reported results were unchanged when using data from which univariate $(z$ scores $<-3.29$ or $>3.29)$ and multivariate (Mahalanobis distance-based) outliers had been eliminated, we present the results based on the full dataset. As mentioned above, for the HLM analysis, we used the robust SE estimates to safeguard against outliers.

\section{Results}

\section{Preliminary analyses: behavioral analyses}

As expected, superior inhibitory control on the flanker task predicted faster responses on both high and low reward value trials (Spearman's rho values of 0.20 and 0.16 , respectively, both $p$ values $<0.005)$, as well in both working memory conditions (Spearman's rho values of 0.19 and 0.24 , respectively, both $p$ values $<0.001)$. Individuals with better inhibitory control also made more accurate responses in the two-back working condition (Spearman's rho of $0.23, p<0.001$ ). More mature age was associated with somewhat slower responses in the two-back condition (Spearman's rho of $-0.12, p=0.02$ ), as well as lower accuracy in the zero-back condition (Spearman's rho of -0.12 , $p=0.02$ ), but showed no significant correlation with the remain- ing behavioral variables (all $p$ values $>0.07$ ). Albeit statistically significant, the correlations between age and behavioral performance were quite small, implying that, within a young adult group, age can explain a relatively modest amount of variance in cognitive and social-affective performance.

\section{Brain analyses}

Modularity in the high versus the low reward or cognitive load conditions

To test for differences in modularity in the high versus the low reward or cognitive load conditions, we conducted two-level hierarchical linear regression analyses (HLM 7.01) (Raudenbush et al., 2013) with robust SEs to safeguard against potential outliers (Raudenbush and Bryk, 2002). For these analyses, we averaged the modularity indices within the two low-reward (financial loss, random movement) and high-reward (financial gain, social movement) conditions, respectively. In these models, the modularity indices (Level 1) were embedded in participants (Level 2). A dummy variable coded zero for the low reward/cognitive load condition and 1 for high reward/cognitive load condition was introduced as the Level 1 predictor. For the sake of consistency with the main results, we present below only the findings obtained when average motion per participant in the socialaffective or cognitive context was introduced as Level 2 covariate of no interest. Nonetheless, all the results presented below remain identical if average motion per participant is not introduced as a Level 2 covariate. Results of two separate HLM regression analyses provided evidence that modularity was signif- 
a

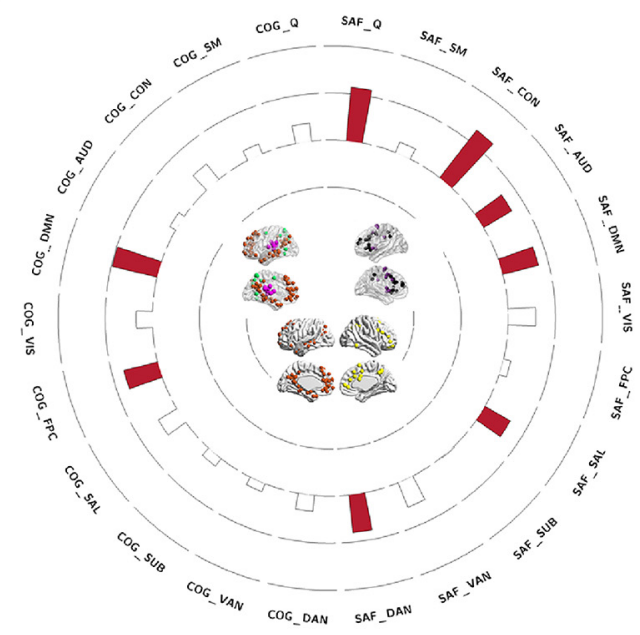

b

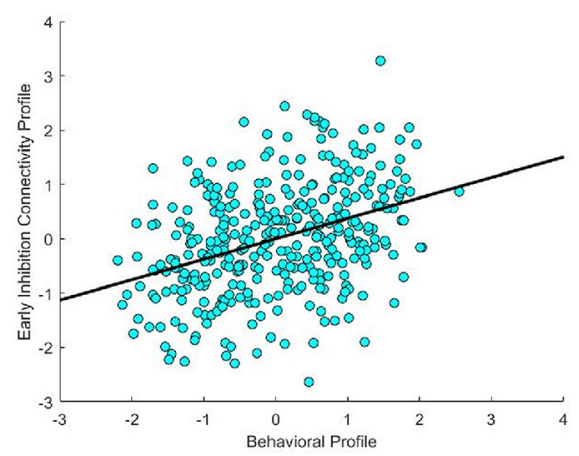

C

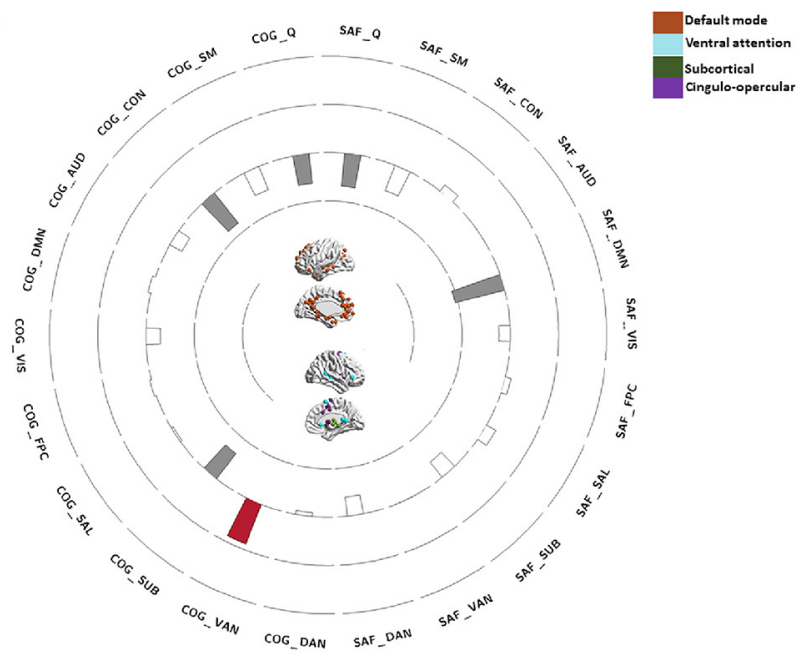

d

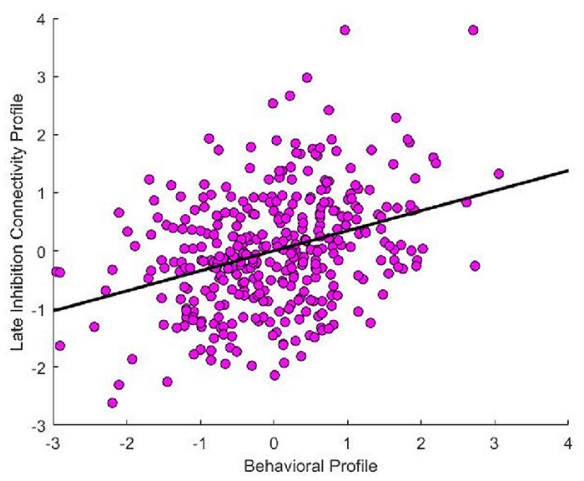

Figure 2. The loadings of the brain variables corresponding to Mode $1(\boldsymbol{a})$ and Mode $2(\boldsymbol{c})$ from CCA 2 on their corresponding canonical variates and the scatter plots describing the linear association between the brain and the behavioral (i.e., age and inhibitory control) canonical variates ( $\boldsymbol{b}, \boldsymbol{d})$. $\boldsymbol{a}, \boldsymbol{c}, \mathbf{C O G}$, Working memory context; SAF_, social-affective context; $\mathbf{Q}$, whole-brain modularity metric. $\boldsymbol{a}, \boldsymbol{c}$, Networks with significant loadings on the respective brain variate are represented in the middle of each circular plot, separately for the cognitive (on the left side) versus the social-affective (on the right side) context. In each circular plot, bars in red represent positive loadings of a brain variable on its variate. Bars in gray represent negative loadings of a brain variable on its variate. In each circular plot, the outermost ring represents a canonical loading of 1.0 and the second ring (from the outside) represents a canonical loading of 0.50 . Complementarily, the innermost ring represents a canonical loading of -1.0 , whereas the second ring from the center of the circular plot represents a canonical loading of -0.50 . The networks presented in Figures 1 and 2 were visualized with the BrainNet Viewer (Xia et al., 2013).

icantly reduced in the high, compared with low, reward $(b=$ $\left.-0.004, \mathrm{SE}=0.001, t_{(357)}=-3.02, p=0.003\right)$ and cognitive load condition alike $\left(b=-0.024, \mathrm{SE}=0.002, t_{(357)}=-15.55, p<0.001\right)$ (for reduced modularity with increasing cognitive load, see also Vatansever et al., 2015; Braun et al., 2015).

\section{Control brain variables}

Because the community detection analyses were conducted separately for each participant, a different number of communities was identified for each individual in each scrutinized task condition or context. There was no statically significant correlation between either age or inhibition and the number of dynamic communities identified in the social-affective context or the number of stable communities identified in the Social, Random, Gain, Loss, or Two-Back conditions (all $p$ values $>0.18$ ). There were weak, albeit statistically significant, positive associations between inhibitory control and the number of dynamic communities identified in the cognitive context $\left(r_{(357)}=0.10, p=0.05\right)$ as well as between age and the number of communities identified in the zero-back condition $\left(r_{(357)}=0.12, p=0.02\right)$. Therefore, because the focus of our present study was on system-specific segregation and whole-brain modularity, we opted to include the number of communities identified in each of the six experimental conditions and each of the two task contexts as covariates of no interest in our analyses.

\section{CCA}

In both canonical correlation analyses described below, age (in years) and inhibitory control (from the flanker task) were entered as the behavioral variables. Our main analyses used the wholebrain modularity measures and the network segregation estimates aggregated across the three values of the gamma parameter and two types of negative weight treatment (i.e., symmetrical vs asymmetrical). Nonetheless, in Tables 2, 4, and 6, we present the results of analyses using estimates from each of the six combinations of gamma values and negative weight treatment, so that the reader could get a sense of the robustness of our findings against variations in the settings of the community detection algorithm.

CCA 1: dynamic connectivity

This analysis revealed one significant CCA mode $(r=0.37, p<$ 0.0001 ; for loadings of each dynamic connectivity variable on its canonical variate, see Fig. $1 a$; for the relationship between the brain and behavioral canonical variates, see Fig. $1 b$ ). This mode 
characterized the dynamic connectivity patterns of younger individuals (for the negative loading and standardized coefficient of age, see Table 1), particularly those with superior inhibition (for the positive loading and standardized coefficient of inhibition, as well as for standardized coefficients for age and inhibition, both of which are $>0.30$, pointing to their independent, additive effects, see Table 1). Thus, across both contexts, younger individuals with superior inhibition demonstrated greater temporal cohesion in the DMN, CON, and SAL (for canonical loadings across all gamma treatment of negative weights combinations, see Table 2). That is, across time, as a function of increasing inhibitory control, the nodes within each of these three networks were increasingly more likely to interact with one another rather than with nodes from other networks. An inspection of the standardized coefficients in Table 1 suggests that the aforementioned effects are mainly driven by the $\mathrm{CON}$ in the social-affective context and by the SAL in the cognitive context. More broadly, though, these findings are consistent with the idea that high temporal coherence in the DMN, CON, and SAL is a neural trait that is best expressed by younger individuals and that is associated with positive cognitive consequences (i.e., superior inhibitory control).

In addition to the aforementioned context-free effects, the same CCA also provided evidence of context-specific functional interaction patterns, such that, during the social-affective, but not the cognitive task, younger individuals with superior inhibitory control showed greater spatiotemporal modularity at the whole-brain level, as well as additional spatiotemporal segregation effects in the FPC and VIS (Tables 1, 2; Fig. 1a).

\section{CCA 2: stable connectivity}

This analysis revealed two significant orthogonal CCA modes, linking brain connectivity patterns to superior inhibition, either during earlier $(r=0.38, p<0.0001)$ or later $(r=0.35, p=0.003)$ stages of younger adulthood.

\section{Mode 1: inhibition during earlier adulthood}

The first extracted CCA mode characterized brain connectivity patterns linked to superior inhibition during earlier adulthood (for loadings of each stable connectivity variable on its canonical variate, see Fig. $2 a$; for the relationship between the brain and behavioral canonical variates, see Fig. $2 b$ ). Across both task contexts, younger individuals with superior inhibitory control demonstrated greater system segregation (for all canonical loadings and standardized coefficients from this analysis using the modularity values aggregated across all gamma values and treatment of negative weights conditions, see Table 3; for canonical loadings for each gamma treatment of negative weights combination, see Table 4). Common to both contexts was a link between superior inhibition and greater DMN segregation. Context-specific associations between system segregation and superior inhibition were observed in the FPC under high cognitive load, as well as in the CON, SAL, DAN, and AUD/language in response to more rewarding stimuli. As we found with the dynamic connectivity results, this analysis provided evidence of a link between superior inhibitory control in younger adulthood and greater whole-brain modularity in the high-reward value condition only. An inspection of the standardized coefficients in Table 3 reveals that the strongest unique network contributions to this brain variate are made independently by the DMN and FPC under high cognitive load and by the $\mathrm{CON}$ in response to high reward stimuli.

\section{Mode 2: inhibition during later adulthood}

The second extracted CCA mode reflected the brain connectivity patterns most strongly linked to superior inhibition in later adult-
Table 3. CCA 2-Mode 1: static functional connectivity patterns linked to superior inhibitory control during earlier adulthood ${ }^{a}$

\begin{tabular}{lll}
\hline Variable & $\begin{array}{l}\text { Canonical } \\
\text { loadings }\end{array}$ & $\begin{array}{l}\text { Standardized } \\
\text { coefficients }\end{array}$ \\
\hline
\end{tabular}

Brain LV

Social-affective

Somatomotor

Cingulo-opercular

Auditory

Default mode

Visual

Frontoparietal

Salience

Subcortical

Ventral attention

Dorsal attention

Whole-brain spatial modularity

Cognitive

Somatomotor

Cingulo-opercular

Auditory

Default mode

Visual

Frontoparietal

Salience

Subcortical

Ventral attention

Dorsal attention

Whole-brain spatial modularity

Behavioral LV

Age

Inhibitory control

$\begin{array}{lr}0.12 & -0.06 \\ 0.64^{b} & 0.53 \\ 0.35^{b} & 0.21 \\ 0.39^{b} & 0.00 \\ 0.29 & 0.10 \\ 0.08 & -0.27 \\ 0.30^{b} & 0.11 \\ 0.01 & -0.23 \\ 0.28 & 0.19 \\ 0.40^{b} & 0.19 \\ 0.57^{b} & 0.25 \\ & \\ 0.11 & 0.06 \\ 0.21 & -0.07 \\ 0.07 & 0.07 \\ 0.49^{b} & 0.34 \\ 0.17 & 0.08 \\ 0.37^{b} & 0.35 \\ 0.23 & 0.06 \\ 0.10 & 0.02 \\ 0.09 & -0.06 \\ 0.17 & 0.03 \\ 0.19 & -0.23 \\ & \\ -0.93^{b} & -0.90 \\ 0.45^{b} & 0.37\end{array}$

${ }^{a} \mathrm{LV}$, Latent variable.

${ }^{b}$ Canonical loadings with absolute values $>0.30$.

hood (for all canonical loadings and standardized coefficients from this analysis using the modularity values aggregated across all gamma values and treatment of negative weight conditions, see Table 5; for canonical loadings for each scrutinized gamma treatment of negative weights combination, see Table 6; for loadings of each stable connectivity variable on its canonical variate, see Fig. $2 c$; for the relationship between the brain and behavioral canonical variates, see Fig. 2 d). Thus, more mature individuals with superior inhibition showed reduced whole-brain modularity in both contexts, reduced segregation in the DMN in response to more rewarding stimuli, as well as reduced segregation in the CON and SUB in response to greater cognitive load. In contrast, increased VAN segregation was found in those older individuals with better inhibitory function in response to greater cognitive load. An inspection of the standardized coefficients in Table 5 suggests that higher scorers on the brain variate of this CCA mode are those that, in response to higher reward value stimuli, show relatively reduced DMN, but increased CON, segregation (compared with the remaining brain indices), whereas in response to cognitive load, they show relatively reduced CON segregation (i.e., greater integration), but increased VAN segregation.

\section{Control analyses}

To verify that the association of age and inhibition with the identified connectivity profiles remains significant after controlling for potential global connectivity and community structure variables, as well as demographic confounds, we first computed canonical variate scores for each participant on each of the three identified connectivity profiles and their associated behavioral profiles (i.e., the values plotted in Figs. 1, 2, which are based on 
Table 4. Control analyses for CCA 2 (Mode 1): canonical correlation coefficients and loadings for the analyses using connectivity indices obtained with alternate community detection parameters (gamma resolution factor, treatment of negative weights) ${ }^{a}$

\begin{tabular}{|c|c|c|c|c|c|c|}
\hline Variable & $\begin{array}{l}\mathrm{A} / 0 \\
(r=0.38)^{*}\end{array}$ & $\begin{array}{l}\mathrm{A} / 1 \\
(r=0.38)^{*}\end{array}$ & $\begin{array}{l}\mathrm{A} / 2 \\
(r=0.38)^{*}\end{array}$ & $\begin{array}{l}\mathrm{S} / 0 \\
(r=0.39)^{*}\end{array}$ & $\begin{array}{l}\mathrm{S} / 1 \\
(r=0.38)^{*}\end{array}$ & $\begin{array}{l}\mathrm{S} / 2 \\
(r=0.37)^{*}\end{array}$ \\
\hline \multicolumn{7}{|l|}{ Brain LV } \\
\hline \multicolumn{7}{|l|}{ Social-affective } \\
\hline Somatomotor & 0.12 & 0.09 & 0.11 & 0.11 & 0.09 & 0.11 \\
\hline Cingulo-opercular & $0.63^{b}$ & $0.64^{b}$ & $0.64^{b}$ & $0.62^{b}$ & $0.64^{b}$ & $0.65^{b}$ \\
\hline Auditory & $0.34^{b}$ & $0.34^{b}$ & $0.35^{b}$ & $0.34^{b}$ & $0.35^{b}$ & $0.35^{b}$ \\
\hline Default mode & $0.40^{b}$ & $0.34^{b}$ & $0.39^{b}$ & $0.37^{b}$ & $0.35^{b}$ & $0.38^{b}$ \\
\hline Visual & 0.30 & 0.28 & 0.29 & 0.29 & 0.29 & 0.29 \\
\hline Frontoparietal & 0.08 & 0.08 & 0.08 & 0.08 & 0.08 & 0.08 \\
\hline Salience & $0.30^{b}$ & $0.31^{b}$ & $0.30^{b}$ & $0.30^{b}$ & $0.31^{b}$ & $0.31^{b}$ \\
\hline Subcortical & 0.01 & -0.01 & 0.01 & 0.00 & -0.01 & 0.00 \\
\hline Ventral attention & 0.28 & 0.28 & 0.28 & 0.28 & 0.28 & 0.29 \\
\hline Dorsal attention & $0.41^{b}$ & $0.38^{b}$ & $0.40^{b}$ & $0.39^{b}$ & $0.39^{b}$ & $0.40^{b}$ \\
\hline Whole-brain spatiotemporal modularity & $0.37^{b}$ & $0.36^{b}$ & $0.35^{b}$ & $0.31^{b}$ & $0.46^{b}$ & $0.29^{b}$ \\
\hline \multicolumn{7}{|l|}{ Cognitive } \\
\hline Somatomotor & 0.12 & 0.09 & 0.11 & 0.10 & 0.09 & 0.11 \\
\hline Cingulo-opercular & 0.22 & 0.17 & 0.21 & 0.20 & 0.18 & 0.20 \\
\hline Auditory & 0.07 & 0.05 & 0.07 & 0.06 & 0.06 & 0.07 \\
\hline Default mode & $0.48^{b}$ & $0.49^{b}$ & $0.49^{b}$ & $0.48^{b}$ & $0.49^{b}$ & $0.49^{b}$ \\
\hline Visual & 0.17 & 0.16 & 0.17 & 0.16 & 0.16 & 0.17 \\
\hline Frontoparietal & $0.37^{b}$ & $0.37^{b}$ & $0.37^{b}$ & $0.36^{b}$ & $0.37^{b}$ & $0.38^{b}$ \\
\hline Salience & 0.23 & 0.23 & 0.23 & 0.22 & 0.23 & 0.23 \\
\hline Subcortical & 0.11 & 0.06 & 0.09 & 0.09 & 0.07 & 0.09 \\
\hline Ventral attention & 0.08 & 0.13 & 0.10 & 0.10 & 0.13 & 0.11 \\
\hline Dorsal attention & 0.17 & 0.16 & 0.17 & 0.16 & 0.16 & 0.17 \\
\hline Whole-brain spatiotemporal modularity & -0.02 & 0.12 & 0.09 & 0.06 & 0.18 & 0.12 \\
\hline \multicolumn{7}{|l|}{ Behavioral LV } \\
\hline Age & -0.94 & -0.89 & -0.93 & -0.92 & -0.89 & -0.92 \\
\hline Inhibitory control & $0.42^{b}$ & $0.54^{b}$ & $0.46^{b}$ & $0.47^{b}$ & $0.53^{b}$ & $0.47^{b}$ \\
\hline
\end{tabular}

${ }^{a} \mathrm{LV}$, Latent variable; $\mathrm{A} / 0$, asymmetrical treatment of negative weights/gamma value of $0 ; \mathrm{A} / 1$, asymmetrical treatment of negative weights/gamma value of $1 ; \mathrm{A} / 2$, asymmetrical treatment of negative weights/gamma value of 2; S/0, symmetrical treatment of negative weights/gamma value of $0 ; S / 1$, symmetrical treatment of negative weights/gamma value of $1 ; S / 2$, symmetrical treatment of negative weights/gamma value of 2 .

${ }^{b}$ Variables evidencing canonical loadings with absolute values $>0.30$ in our default aggregate condition.

${ }^{*} p<0.0001$.

the whole-brain modularity and system segregation indices aggregated across all six gamma value-negative weight treatment conditions). Results of partial correlation analyses in which we controlled for global connectivity within each of the six stable connectivity task conditions (i.e., average connectivity among all the 229 nodes in the zero-back, two-back, social, random, financial reward and loss conditions, respectively), number of communities identified in each of the six stable connectivity conditions, as well as in each of the two dynamic connectivity contexts (i.e., working memory and social-affective task, respectively), sex (compare Satterthwaite et al., 2015; Scheinost et al., 2015), handedness, and years of education, revealed that the association between the identified connectivity and behavioral profiles remained virtually unchanged (all $p$ values $<0.0001$ ).

Connectivity profiles and in-scanner behavioral performance To test whether the identified connectivity profiles are associated with in-scanner behavioral performance, we conducted a canonical correlation analysis. The behavioral set included the speed scores on the high- versus low-reward value trials, as well as the two- and zero-back accuracy and speed scores. The brain set encompassed the canonical variate scores on the three identified connectivity profiles associated with inhibitory control. This analysis revealed one significant CCA mode $(r=0.31, p=0.001$; for canonical loadings, see Table 7), which linked superior performance on all tasks, but particularly accuracy on the two-back working memory task (see standardized coefficients in Table 7), to greater expression of the dynamic connectivity profile (i.e., greater context-free spatiotemporal segregation in the $\mathrm{DMN}, \mathrm{CON}$, and SAL, as well as greater whole-brain modularity coupled with greater FPC and VIS segregation in the social-affective context) and of the stable connectivity profile associated with inhibition during later adulthood (i.e., reduced DMN segregation and whole-brain modularity in the high reward condition, coupled with reduced CON and SUB, but greater VAN, segregation in the high cognitive load condition). An inspection of the standardized coefficients in Table 7 suggests that the dynamic and later adulthood stable connectivity profiles are independently related to working memory performance. The association between the connectivity variates and behavioral performance (i.e., accuracy in the two- and zero-back working memory conditions, as well as speed in the zero-back condition and on the social-affective task, see Table 7) remained significant at $p<0.0001$, after controlling for global connectivity and number of communities within each of the six stable connectivity task conditions, number of communities identified in each of the two dynamic connectivity contexts, age, years of education, sex, and handedness.

\section{Inhibition-linked connectivity profiles and psychological functioning}

Finally, we sought to shed some light on the "real-life" behavioral relevance of the three identified connectivity profiles. Specifically, given their relationship with age, we were interested in whether these connectivity profiles would have age-varying relationships with psychological functioning. To this end, we specified a two-level HLM model, in which standardized scores on the 
Table 5. CCA 2-Mode 2: static functional connectivity patterns linked to superior inhibitory control during later adulthood ${ }^{a}$

\begin{tabular}{|c|c|c|}
\hline Variable & $\begin{array}{l}\text { Canonical } \\
\text { loadings }\end{array}$ & $\begin{array}{l}\text { Standardized } \\
\text { coefficients }\end{array}$ \\
\hline \multicolumn{3}{|l|}{ Brain LV } \\
\hline \multicolumn{3}{|l|}{ Social-affective } \\
\hline Somatomotor & -0.28 & -0.17 \\
\hline Cingulo-opercular & 0.08 & 0.32 \\
\hline Auditory & 0.00 & 0.00 \\
\hline Default mode & $-0.53^{b}$ & -0.47 \\
\hline Visual & -0.12 & -0.04 \\
\hline Frontoparietal & 0.06 & 0.13 \\
\hline Salience & 0.11 & 0.20 \\
\hline Subcortical & -0.20 & -0.15 \\
\hline Ventral attention & 0.00 & 0.04 \\
\hline Dorsal attention & -0.20 & -0.04 \\
\hline Whole-brain spatial modularity & $-0.34^{b}$ & -0.18 \\
\hline \multicolumn{3}{|l|}{ Cognitive } \\
\hline Somatomotor & -0.26 & -0.24 \\
\hline Cingulo-opercular & $-0.40^{b}$ & -0.38 \\
\hline Auditory & -0.14 & 0.11 \\
\hline Default mode & 0.03 & 0.22 \\
\hline Visual & -0.15 & -0.11 \\
\hline Frontoparietal & 0.02 & 0.17 \\
\hline Salience & -0.02 & 0.11 \\
\hline Subcortical & $-0.33^{b}$ & -0.23 \\
\hline Ventral attention & $0.44^{b}$ & 0.42 \\
\hline Dorsal attention & -0.04 & -0.05 \\
\hline Whole-brain spatial modularity & $-0.30^{b}$ & -0.20 \\
\hline \multicolumn{3}{|l|}{ Behavioral LV } \\
\hline Age & $0.37^{b}$ & 0.45 \\
\hline Inhibitory control & $0.89^{b}$ & 0.94 \\
\hline
\end{tabular}

${ }^{a} \mathrm{LV}$, Latent variable.

${ }^{b}$ Canonical loadings with absolute values $>0.30$.

eight ASR subscales (Level 1) were nested within individuals (Level 2). As Level 2 predictors, we included age, scores on the three connectivity profiles, and their interaction with age, as well as sex, handedness, years of education, number of communities identified in each of the two dynamic connectivity contexts, global connectivity, and number of communities within each of the six stable connectivity task conditions as covariates of no interest. The robust SE results from this analysis revealed only a significant two-way interaction between age and scores on the late inhibition connectivity profile (Fig. 3 ; Table $8, \gamma_{024}$ ). To shed some light on this interaction, we used the online utility for two-way multilevel interactions (http://www.quantpsy.org/interact/hlm2.htm) (Preacher et al., 2006). An assessment of the slopes, intercepts (Table 8 ), and variance-covariance coefficients indicated that, in the present sample, the association between scores on the late inhibition profile and psychological problems starts becoming significant at $p<0.05$ only at its upper boundary (i.e., the estimated lower boundary is not represented in the current sample), that is, for individuals older than 30 years of age (i.e., those whose age is $>0.4232$ SDs above the sample's average age). At this region-of-significance boundary, the association between scores on the late inhibition profile and psychological problems is negative $(b=-0.0657, \mathrm{SD}=0.0334, t=$ -1.972 ). As can be inferred from Figure 3 , the interaction effect can be interpreted as evidence that expression of the late inhibitionlinked neural profile after the age of 30 shields against psychological problems (i.e., adults $>30$ who express this profile more strongly show fewer psychological problems than those $>30$ who show a weaker expression of this profile).

\section{Discussion}

To our knowledge, the present study is among the first to probe the interplay between contextual and late developmental effects on the neural architecture relevant to inhibition, the putative core component of cognitive control (Friedman et al., 2008; Miyake and Friedman, 2012). Thus, using whole-brain functional connectivity measures from a large young adult sample, we document similarities and differences in the dynamic and stable neural architecture of inhibition across two task contexts, varying in cognitive load and reward value. Broadly, we provide evidence of distinguishable neural profiles associated with superior inhibition during earlier versus later stages of young adulthood. The former profile is characterized by greater system segregation, and it emerges both in stable and dynamic connectivity patterns. The latter profile is typified by a combination of segregation and integration in a smaller number of systems, and it emerges only in the stable connectivity patterns associated with increasing cognitive load or reward value. Of note, it is failure to develop this profile before the age of 30 that is linked to real-life psychological problems.

The more complex neural signature of superior inhibition, herein documented, emerged during earlier adulthood in both stable and dynamic connectivity analyses and was associated with both context-invariant and context-specific connectivity patterns. Thus, in both stable and dynamic connectivity analyses, younger individuals with superior inhibitory control demonstrated greater context-free segregation in the DMN, the system most relevant to internally oriented cognition (Andrews-Hanna et al., 2014; Spreng et al., 2014; Konishi et al., 2015; D. V. Smith et al., 2015; Spreng and Andrews-Hanna, 2015). Dynamically, context-free, inhibition-linked segregation was further observed in the CON and the SAL. Interestingly, the SAL, as the network linked to environmentally driven behavioral control (Seeley et al., 2007; Sridharan et al., 2008), seemed particularly important in cognitive contexts, such as the HCP working memory task that required continual updating of internal representations based on external information. Complementarily, the CON as the system linked to maintaining vigilance to the external environment within a task context (Dosenbach et al., 2007; Sadaghiani and D'Esposito, 2015) played a key role in the social-affective task, which featured more ambiguous stimuli that necessitated integration of a broader array of incoming information.

Beyond context-free effects, younger individuals with superior inhibition also demonstrated context-specific connectivity patterns. For the cognitive context, with increasing mental load, this was observed only in the stable connectivity patterns of the FPC, the network involved in top-down initiation of control (Spreng et al., 2010). For the social-affective task, the inhibitionlinked segregation was observed in a larger number of systems, both in dynamic and stable whole-brain connectivity patterns. With respect to specific networks, it was observed in the dynamics of the VIS and of the FPC. In stable connectivity analyses, in response to stimuli of greater reward value, inhibition-linked segregation was most clearly observed in systems linked to perceptual and attentional processing (DAN, AUD), as well as those involved in initiating and maintaining control based on environmental demands (CON, SAL) (Corbetta et al., 2000; Corbetta and Shulman, 2002; Dosenbach et al., 2007; DiQuattro et al., 2014; Sadaghiani and D'Esposito, 2015). Thus, in response to rewarding stimuli, younger individuals with superior inhibition show greater externally oriented attentional focus. This pattern of responding is distinct from the one evoked under cognitively challenging circumstances and implies that greater engagement with 
Table 6. Control analyses for CCA 2 (Mode 2): canonical correlation coefficients and loadings for the analyses using connectivity indices obtained with alternate community detection parameters (gamma resolution factor, treatment of negative weights) ${ }^{a}$

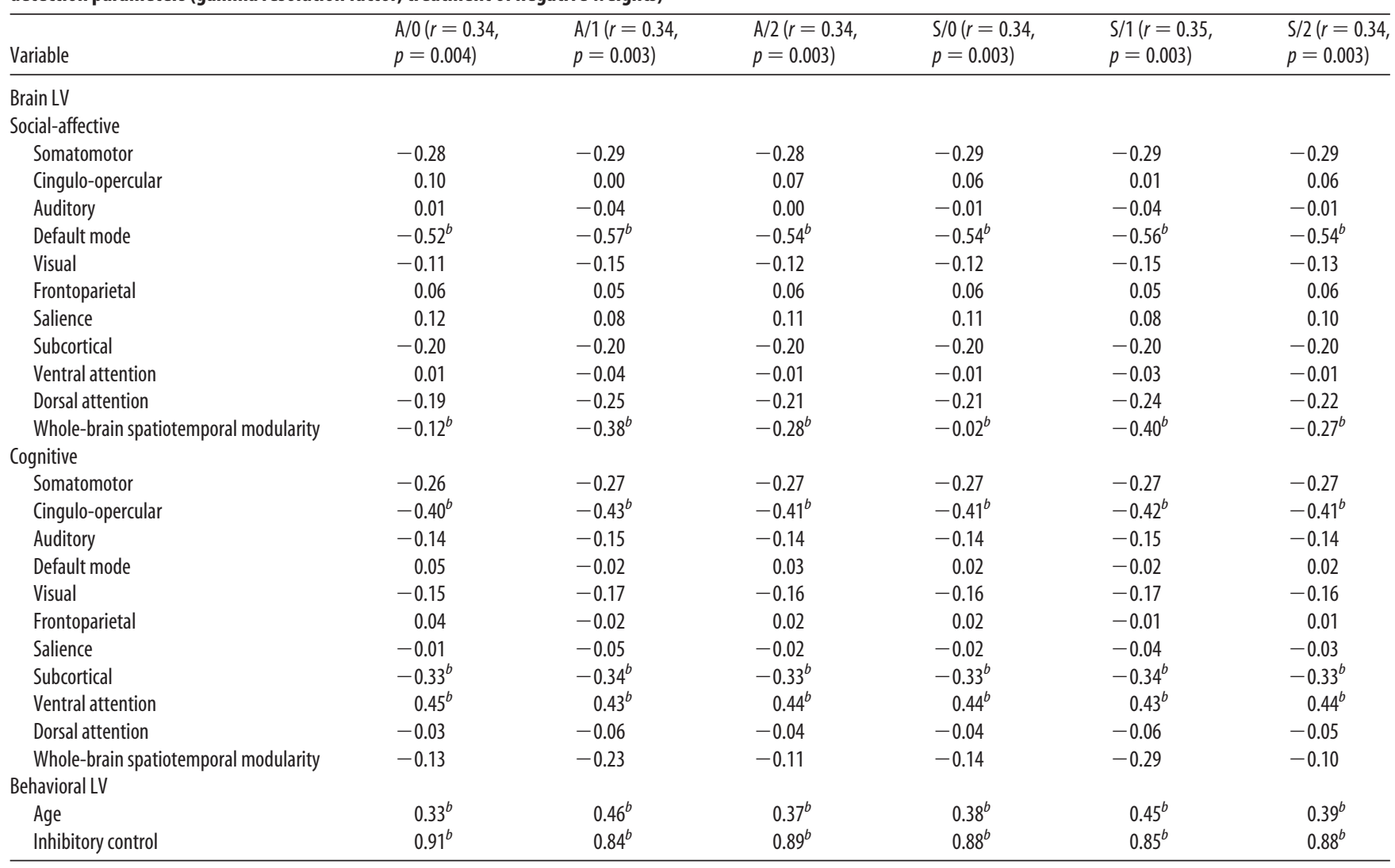

${ }^{a} \mathrm{LV}$, Latent variable; $\mathrm{A} / 0$, asymmetrical treatment of negative weights/gamma value of $0 ; \mathrm{A} / 1$, asymmetrical treatment of negative weights/gamma value of $1 ; \mathrm{A} / 2$, asymmetrical treatment of negative weights/gamma value of 2; S/0, symmetrical treatment of negative weights/gamma value of $0 ; S / 1$, symmetrical treatment of negative weights/gamma value of $1 ; S / 2$, symmetrical treatment of negative weights/gamma value of 2 .

${ }^{b}$ Variables evidencing canonical loadings with absolute values $>0.30$ in our default aggregate condition.

Table 7. Canonical correlation of the in-scanner behavioral performance scores with the inhibition-linked connectivity profiles ${ }^{a}$

\begin{tabular}{llc}
\hline Variable & $\begin{array}{l}\text { Canonical } \\
\text { loadings }\end{array}$ & $\begin{array}{l}\text { Standardized } \\
\text { coefficients }\end{array}$ \\
\hline Brain LV & & \\
$\quad$ Dynamic connectivity profile & $0.83^{b}$ & 0.93 \\
Static connectivity profile earlier adulthood & 0.22 & -0.21 \\
$\quad$ Static connectivity profile later adulthood & $0.53^{b}$ & 0.53 \\
Behavioral LV & & \\
Two-back accuracy & $0.81^{b}$ & 0.60 \\
Zero-back accuracy & $0.57^{b}$ & -0.02 \\
Two-back speed & 0.24 & -0.36 \\
Zero-back speed & $0.72^{b}$ & 0.57 \\
Speed on low reward trials & $0.50^{b}$ & 0.11 \\
Speed on high reward trials & $0.57^{b}$ & 0.25 \\
\hline
\end{tabular}

${ }^{a} \mathrm{LV}$, Latent variable.

${ }^{b}$ Canonical loadings with absolute values $>0.30$.

motivationally relevant information may be an important mechanism underlying successful inhibition.

Interestingly, our documented context-free neural correlates of inhibition in younger adulthood fit well with existing theories of cognitive control. For example, greater modularity presumably reflects more specialized and efficient processing, which is more resilient in the face of environmental challenges (Kashtan and Alon, 2005; Kashtan et al., 2007; Braun et al., 2015; Betzel et al., 2016; Sporns and Betzel, 2016). Such a processing mode seems particularly well suited to facilitate the concurrent maintenance and manipulation of incoming task-relevant informa- tion, key features of inhibitory control (Miyake and Friedman, 2012). Furthermore, the DMN as the pivotal network involved in self-generated representations (Andrews-Hanna et al., 2014; Spreng et al., 2014; Spreng and Andrews-Hanna, 2015) and the functional component most consistently linked to inhibition in the current study, seems to be a likely mechanism underlying the successful maintenance of current task-relevant internal representations, another core feature of inhibition (Friedman et al., 2008; Miyake and Friedman, 2012). Complementarily, the two networks expressing dynamically the inhibition-linked segregation across both cognitive and social-affective contexts (i.e., the CON and SAL) seem particularly well suited to fulfill a third core function of inhibition, specifically, bias perceptual processing in the direction of task-relevant information (Miyake and Friedman, 2012). Indeed, the SAL reportedly orchestrates behavioral control based on the detection of relevant (including task-relevant) environmental information (Seeley et al., 2007; Sridharan et al., 2008), whereas the CON allegedly supports continued alertness to taskrelevant information originating in the external environment (Sadaghiani and D'Esposito, 2015).

Importantly, our investigation identified inhibition-linked neural signatures not only during the earlier, but also the later, stages of young adulthood. The more mature inhibition-linked neural profile emerged only in static connectivity analyses as a function of greater cognitive load or reward value, and it was characterized by reduced context-free whole-brain modularity, as well as reduced segregation in a small number of systems, specifically, the DMN for the social-affective context and the CON and SUB for the cognitive context. The role of the DMN for 


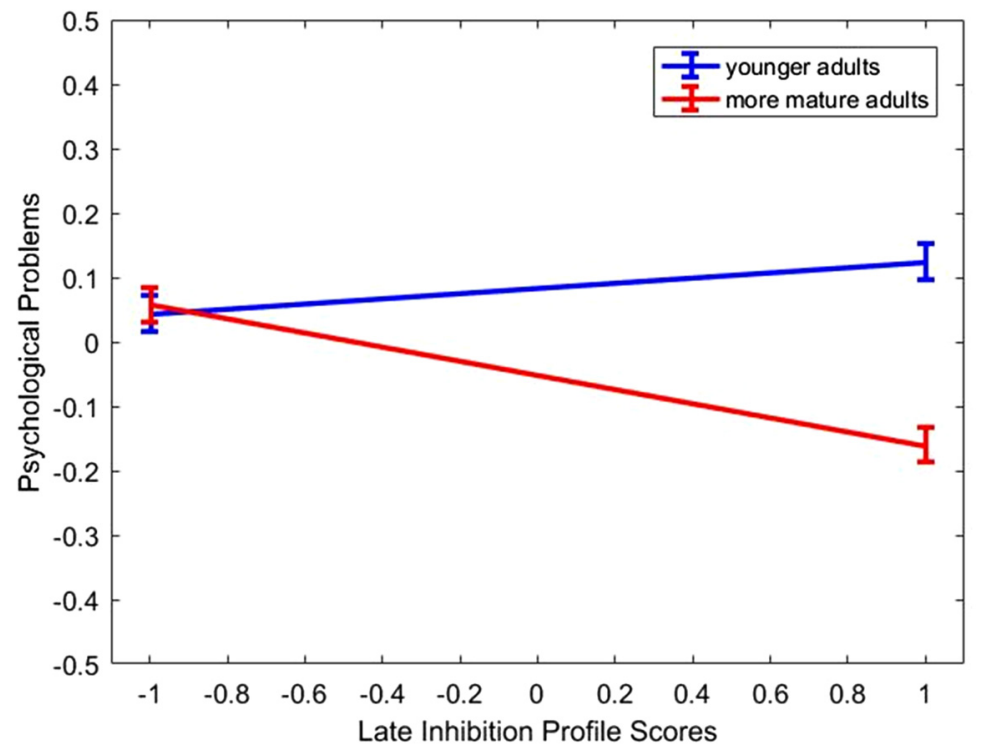

Figure 3. The relationship between life functioning and scores on the late inhibition profile as a function of age. The representations are based on estimates from the HLM model presented in Table 8 , in which all other predictors apart from age, scores on the later adulthood inhibition profile, and their interaction term have been set to their mean value. Although age was used as a continuous variable in the analyses, for the purpose of graphing the interaction, it is broken into younger (i.e., 1 SD below the average age of the sample) and more mature adulthood (i.e., 1SD above the average age of the sample).

Table 8. Results of the HLM analysis predicting psychological functioning from the three identified connectivity profiles and their interaction with age ${ }^{a}$

\begin{tabular}{|c|c|c|c|c|}
\hline Fixed effect & Coefficient & SE & tratio & $p$ \\
\hline Intercept, $\gamma_{00}$ & 0.016 & 0.050 & 0.328 & 0.743 \\
\hline ex,$\gamma_{01}$ & -0.032 & 0.070 & -0.455 & 0.649 \\
\hline Age, $\gamma_{02}$ & -0.068 & 0.035 & -1.921 & 0.056 \\
\hline Handedness, $\gamma_{03}$ & 0.032 & 0.036 & 0.889 & 0.374 \\
\hline ars of education, $\gamma_{04}$ & -0.141 & 0.038 & -3.741 & $<0.001$ \\
\hline lobal connectivity Two-back, $\gamma_{05}$ & 0.009 & 0.105 & 0.087 & 0.931 \\
\hline obal connectivity Zero-back, & 0.001 & 0.075 & 0.008 & 0.994 \\
\hline obal & -0.197 & 124 & -1.589 & 0.113 \\
\hline$\gamma_{08}$ & -0.076 & 083 & -0.920 & 0.358 \\
\hline nnectivity Gain, $\gamma_{09}$ & 0.023 & 0.099 & 0.229 & 0.819 \\
\hline . & 0.126 & 0.102 & 1.238 & 0.216 \\
\hline s (social-affective), $\gamma_{011}$ & -0.004 & 0.036 & -0.105 & 0.916 \\
\hline No. of communities (cognitive), $\gamma_{012}$ & 0.001 & 0.032 & 0.037 & 0.971 \\
\hline of communi & 0.087 & 0.102 & 0.852 & 0.395 \\
\hline of communities Zero-back, $\gamma_{014}$ & 0.013 & 0.071 & 0.178 & 0.859 \\
\hline No. of communities Loss, $\gamma_{015}$ & 0.118 & 0.125 & 0.942 & 0.347 \\
\hline No. of communities Random, $\gamma_{016}$ & 0.084 & 0.079 & 1.062 & 0.289 \\
\hline No. of communities Gain, $\gamma_{017}$ & -0.042 & 0.092 & -0.458 & 0.648 \\
\hline of communit & -0.113 & 0.101 & -1.119 & 0.264 \\
\hline Dynamic connectivity scores, $\gamma$ & 0.010 & 0.040 & 0.252 & 0.801 \\
\hline Static connectivity Mode 1 scores, $\gamma_{020}$ & -0.019 & 0.039 & -0.486 & 0.627 \\
\hline Static connectivity Mode 2 scores, $\gamma_{021}$ & -0.034 & 0.033 & -1.028 & 0.305 \\
\hline Dynamic connectivity scores $\times$ Age, $\gamma_{022}$ & -0.014 & 0.036 & -0.376 & 0.707 \\
\hline Static connectivity Mode 1 scores $\times A$ & -0.018 & 0.032 & -0.559 & 0.577 \\
\hline Static connectivity Mode 2 scores $\times$ Age, $\gamma_{024}$ & -0.074 & 0.027 & -2.716 & 0.007 \\
\hline
\end{tabular}

${ }^{a}$ Approximate df for all coefficients $=334$.

social cognition and affective decision making is extensively documented (Andrews-Hanna et al., 2014; Spreng et al., 2014; D. V. Smith et al., 2015; Spreng and Andrews-Hanna, 2015). Our findings thus imply that, among more mature adults with superior inhibition, processing of high reward stimuli is typified by greater whole-brain integration of the most task-relevant network (i.e., the DMN). This raises the question of whether greater whole- brain integration of internal representations constitutes the prevalent processing mode evoked by rewarding stimuli, particularly among the more mature individuals, and whether this processing mode may partially account for the previously documented effects of reward on cognitive control performance (Krawczyk et al., 2007; Watanabe, 2007; Jimura et al., 2010).

Complementarily, with increasing cognitive load, more mature individuals with superior inhibition showed greater integration in the CON, the system involved in maintaining task-related alertness to the environment (e.g., Sadaghiani and D'Esposito, 2015) and the SUB, the system linked to category learning (Helie et al., 2010; van Duijvenvoorde et al., 2016), whose importance is easily defended in the HCP working memory task that features stimuli that fall within recognizable categories (Barch et al., 2013). In the context of the younger adulthood inhibition profile, these results suggest that, with greater maturity, individuals with superior inhibition may switch from relying on highly modular internal cognition systems (DMN, FPC) to networks linked to more externally oriented processing (CON, SUB) that integrate information at the whole-brain level (Helie et al., 2010; Sestieri et al., 2014; Sadaghiani and D'Esposito, 2015). The exception to this developmental trend lies with the VAN, the system linked to bottom-up processing of task-related distracters and unexpected task events (Linden et al., 1999; Corbetta et al., 2000; Corbetta and Shulman, 2002; Fox et al., 2006; DiQuattro et al., 2014; Leitão et al., 2015), which, in the high mental load condition, showed increased segregation among the more mature individuals with superior inhibitory control. This effect, indicative of a narrower attentional focus, may be worth exploring in future research.

Interestingly, it was the expression of this later, but not earlier, stable connectivity inhibition profile that predicted superior task performance. The fact that the behaviorally optimal network organization during more complex tasks is one of reduced system segregation, particularly with respect to the most task-relevant systems, is compatible with extant findings that more demanding cognitive functions, such as those linked to working memory, benefit from a less modular brain organization that fosters better flow of information across its component nodes (e.g., Vatansever et al., 2015; Cohen and D'Esposito, 2016). In the context of our study, we interpret the late inhibition profile as one end product of the neurobehavioral fine-tuning processes assumed to occur during the 20s (e.g., Veroude et al., 2013; Vink et al., 2014; Chai et al., 2014) and culminate in more effective network organization. Thus, among individuals $<30$ years of age, weaker expression of the late inhibition profile is not yet indicative of developmental abnormalities, hence the lack of a significant association with life-functioning problems. In contrast, among individuals $>30$ years of age, when most neurobehavioral fine-tuning processes have presumably concluded, poorer expression of the late inhibition profile likely signals developmental abnormalities or delays, hence its link to life-functioning problems.

In conclusion, we have documented contextual differences in the dynamic and stable neural architecture linked to the putative 
core component of cognitive control. In doing so, we also provided suggestive evidence on the distinguishable neural profiles linked to superior inhibition in younger versus more mature adulthood. More broadly, our findings speak to the importance of probing contextual and developmental factors in gaining a better understanding of the neuro-functional landscape in which a specific trait resides.

\section{References}

Achenbach TM (2009) The Achenbach System of Empirically Based Assessment (ASEBA): development, findings, theory and applications. Burlington, VT: University of Vermont Research Center for Children, Youth and Families.

Alavash M, Doebler P, Holling H, Thiel CM, Gießing C (2015) Is functional integration of resting state brain networks an unspecific biomarker for working memory performance? Neuroimage 108:182-193. CrossRef Medline

Allen EA, Damaraju E, Plis SM, Erhardt EB, Eichele T, Calhoun VD (2014) Tracking whole-brain connectivity dynamics in the resting state. Cereb Cortex 24:663-676. CrossRef Medline

Andrews-Hanna JR, Mackiewicz Seghete KL, Claus ED, Burgess GC, Ruzic L, Banich MT (2011) Cognitive control in adolescence: neural underpinnings and relation to self-report behaviors. PLoS One 6:e21598. CrossRef Medline

Andrews-Hanna JR, Saxe R, Yarkoni T (2014) Contributions of episodic retrieval and mentalizing to autobiographical thought: evidence from functional neuroimaging, resting state connectivity, and fMRI metaanalyses. Neuroimage 91:324-335. CrossRef Medline

Barch DM, Burgess GC, Harms MP, Petersen SE, Schlaggar BL, Corbetta M, Glasser MF, Curtiss S, Dixit S, Feldt C, Nolan D, Bryant E, Hartley T, Footer O, Bjork JM, Poldrack R, Smith S, Johansen-Berg H, Snyder AZ, Van Essen DC (2013) Function in the human connectome: task-fMRI and individual differences in behavior. Neuroimage 80:169-189. Medline

Bassett DS, Wymbs NF, Porter MA, Mucha PJ, Carlson JM, Grafton ST (2011) Dynamic reconfiguration of human brain networks during learning. Proc Natl Acad Sci U S A 108:7641-7646. CrossRef Medline

Bassett DS, Wymbs NF, Rombach MP, Porter MA, Mucha PJ, Grafton ST (2013) Task-based core-periphery organisation of human brain dynamics. PLoS Comput Biol 9:e1003171. CrossRef Medline

Behzadi Y, Restom K, Liau J, Liu TT (2007) A component based noise correction method (CompCor) for BOLD and perfusion based fMRI. Neuroimage 37:90-101. CrossRef Medline

Berger A (2011) Self-regulation in social contexts. In: Self-regulation: brain, cognition, and development, pp 91-103. Washington, DC: American Psychological Association.

Bernard JA, Orr JM, Mittal VA (2016) Differential motor and prefrontal cerebello-cortical network development: evidence from multimodal neuroimaging. Neuroimage 124:591-601. CrossRef Medline

Betzel RF, Byrge L, He Y, Goñi J, Zuo X, Sporns O (2014) Changes in structural and functional connectivity among resting-state networks across the human lifespan. Neuroimage 102:345-357. CrossRef Medline

Betzel RF, Bassett DS (2016) Multi-scale brain networks. Neuroimage. Advance online publication. Retrieved Nov. 11, 2016. doi: 10.1016/j.neuroimage.2016.11.006. CrossRef Medline

Betzel RF, Fukushima M, He Y, Zuo XN, Sporns O (2016) Dynamic fluctuations coincide with periods of high and low modularity in resting-state functional brain networks. Neuroimage 127:287-297. CrossRef Medline

Braun U, Schäfer A, Walter H, Erk S, Romanczuk-Seiferth N, Haddad L, Schweiger JI, Grimm O, Heinz A, Tost H, Meyer-Lindenberg A, Bassett DS (2015) Dynamic reconfiguration of frontal brain networks during executive cognition in humans. Proc Natl Acad Sci U S A 112:1167811683. CrossRef Medline

Castelli F, Happé F, Frith U, Frith C (2000) Movement and mind: a functional imaging study of perception and interpretation of complex intentional movement patterns. Neuroimage 12:314-325. CrossRef Medline

Chai XJ, Ofen N, Gabrieli JD, Whitfield-Gabrieli S (2014) Selective development of anticorrelated networks in the intrinsic functional organization of the human brain. J Cogn Neurosci 26:501-513. CrossRef Medline

Chan MY, Park DC, Savalia NK, Petersen SE, Wig GS (2014) Decreased segregation of brain systems across the healthy adult lifespan. Proc Natl Acad Sci U S A 111:E4997-E5006. CrossRef Medline

Chan MY, Alhazmi FH, Park DC, Savalia NK, Wig GS (2017) Resting-state network topology differentiates task signals across the adult life span. J Neurosci 37:2734-2745. CrossRef Medline

Chang C, Glover GH (2010) Time-frequency dynamics of resting state brain connectivity measured with fMRI. Neuroimage 50:81-98. CrossRef Medline

Chen T, Cai W, Ryali S, Supekar K, Menon V (2016) Distinct global brain dynamics and spatiotemporal organization of the salience network. PLoS Biol 14:21. CrossRef Medline

Church JA, Fair DA, Dosenbach NU, Cohen AL, Miezin FM, Petersen SE, Schlaggar BL (2009) Control networks in paediatric Tourette Syndrome show immature and anomalous patterns of functional connectivity. Brain 132:225-238. CrossRef Medline

Cohen JR, D'Esposito M (2016) The segregation and integration of distinct brain networks and their relationship to cognition. J Neurosci 36:1208312094. CrossRef Medline

Cole MW, Bassett DS, Power JD, Braver TS, Petersen SE (2014) Intrinsic and task-evoked network architectures of the human brain. Neuron 83: 238-251. CrossRef Medline

Corbetta M, Shulman GL (2002) Control of goal-directed and stimulusdriven attention in the brain. Nat Rev Neurosci 3:201-215. CrossRef Medline

Corbetta M, Kincade JM, Ollinger JM, McAvoy MP, Shulman GL (2000) Voluntary orienting is dissociated from target detection in human posterior parietal cortex. Nat Neurosci 3:292-297. CrossRef Medline

Delgado MR, Nystrom LE, Fissell C, Noll DC, Fiez JA (2000) Tracking the hemodynamic responses to reward and punishment in the striatum. J Neurophysiol 84:3072-3077. Medline

Di X, Gohel S, Kim EH, Biswal BB (2013) Task vs. rest-different network configurations between the coactivation and the resting-state brain networks. Front Hum Neurosci 7:493. CrossRef Medline

DiQuattro NE, Sawaki R, Geng JJ (2014) Effective connectivity during feature-based attentional capture: evidence against the attentional reorienting hypothesis of TPJ. Cereb Cortex 24:3131-3141. CrossRef Medline

Dosenbach NU, Fair DA, Miezin FM, Cohen AL, Wenger KK, Dosenbach RA, Fox MD, Snyder AZ, Vincent JL, Raichle ME, Schlaggar BL, Petersen SE (2007) Distinct brain networks for adaptive and stable task control in humans. Proc Natl Acad Sci U S A 104:11073-11078. CrossRef Medline

Engelmann JB, Pessoa L (2007) Motivation sharpens exogenous spatial attention. Emotion 7:668-674. CrossRef Medline

Fair DA, Dosenbach NU, Church JA, Cohen AL, Brahmbhatt S, Miezin FM, Barch DM, Raichle ME, Petersen SE, Schlaggar BL (2007) Development of distinct control networks through segregation and integration. Proc Natl Acad Sci U S A 104:13507-13512. CrossRef Medline

Fair DA, Cohen AL, Dosenbach NU, Church JA, Miezin FM, Barch DM, Raichle ME, Petersen SE, Schlaggar BL (2008) The maturing architecture of the brain's default network. Proc Natl Acad Sci U S A 105:40284032. CrossRef Medline

Fair DA, Posner J, Nagel BJ, Bathula D, Dias TG, Mills KL, Blythe MS, Giwa A, Schmitt CF, Nigg JT (2010) Atypical default network connectivity in youth with attention-deficit/hyperactivity disorder. Biol Psychiatry 68: 1084-1091. CrossRef Medline

Fox MD, Corbetta M, Snyder AZ, Vincent JL, Raichle ME (2006) Spontaneous neuronal activity distinguishes human dorsal and ventral attention systems. Proc Natl Acad Sci U S A 103:10046-10051. CrossRef Medline

Friedman NP, Miyake A, Young SE, Defries JC, Corley RP, Hewitt JK (2008) Individual differences in executive functions are almost entirely genetic in origin. J Exp Psychol Gen 137:201-225. CrossRef Medline

Friston KJ, Buechel C, Fink GR, Morris J, Rolls E, Dolan RJ (1997) Psychophysiological and modulatory interactions in neuroimaging. Neuroimage 6:218-229. Medline

Garrett DD, Samanez-Larkin GR, MacDonald SW, Lindenberger U, McIntosh AR, Grady CL (2013) Moment-to-moment brain signal variability: a next frontier in human brain mapping? Neurosci Biobehav Rev 37:610 624. CrossRef Medline

Gazzaley A, Cooney JW, Rissman J, D’Esposito M (2005) Top-down suppression deficit underlies working memory impairment in normal aging. Nat Neurosci 8:1298-1300. CrossRef Medline

Geerligs L, Rubinov M, Cam-CAN, Henson RNA (2015) State and trait components of functional connectivity: individual differences vary with mental state. J Neurosci 35:13949-13961. CrossRef Medline

Giedd JN, Rapoport JL (2010) Structural MRI of pediatric brain development: what have we learned and where are we going? Neuron 67:728 -734. CrossRef Medline 
Gonzalez-Castillo J, Hoy CW, Handwerker DA, Robinson ME, Buchanan LC, Saad ZS, Bandettini PA (2015) Tracking ongoing cognition in individuals using whole-brain functional connectivity patterns. Proc Natl Acad Sci U S A 112:8762-8767. CrossRef Medline

Good BH, de Montjoye YA, Clauset A (2010) Performance of modularity maximization in practical contexts. Phys Rev E Stat Nonlin Soft Matter Phys 81:046106. CrossRef Medline

Grady C, Sarraf S, Saverino C, Campbell K (2016) Age differences in the functional interactions among the default, frontoparietal control, and dorsal attention networks. Neurobiol Aging 41:159-172. CrossRef Medline

Graham AM, Pfeifer JH, Fisher PA, Carpenter S, Fair DA (2015) Early life stress is associated with default system integrity and emotionality during infancy. J Child Psychol Psychiatry 56:1212-1222. CrossRef Medline

Hair JF, Tatham RL, Anderson RE, Black W (1998) Multivariate data analysis (Ed 5). London: Prentice-Hall.

Hampson M, Driesen NR, Skudlarski P, Gore JC, Constable RT (2006) Brain connectivity related to working memory performance. J Neurosci 26:13338-13343. CrossRef Medline

Helie S, Roeder JL, Ashby FG (2010) Evidence for cortical automaticity in rule-based categorization. J Neurosci 30:14225-14234. CrossRef Medline

Hotelling H (1936) Relations between two sets of variables. Biometrika 28: 321-377. CrossRef

Hübner R, Schlösser J (2010) Monetary reward increases attentional effort in the flanker task. Psychon Bull Rev 17:821-826. CrossRef Medline

Hutchison RM, Morton JB (2015) Tracking the brain's functional coupling dynamics over development. J Neurosci 35:6849-6859. CrossRef Medline

Hutchison RM, Womelsdorf T, Gati JS, Everling S, Menon RS (2013) Resting-state networks show dynamic functional connectivity in awake humans and anesthetized macaques. Hum Brain Mapp 34:2154-2177. CrossRef Medline

Izuma K, Saito DN, Sadato N (2008) Processing of social and monetary rewards in the human striatum. Neuron 58:284-294. CrossRef Medline

Jimura K, Locke HS, Braver TS (2010) Prefrontal cortex mediation of cognitive enhancement in rewarding motivational contexts. Proc Natl Acad Sci U S A 107:8871-8876. CrossRef Medline

Joormann J, D'Avanzato C (2010) Emotion regulation in depression: examining the role of cognitive processes. Cogn Emot 24:913-939. CrossRef

Kaller CP, Heinze K, Mader I, Unterrainer JM, Rahm B, Weiller C, Köstering L (2012) Linking planning performance and gray matter density in middorsolateral prefrontal cortex: moderating effects of age and sex. Neuroimage 63:1454-1463. CrossRef Medline

Kashtan N, Alon U (2005) Spontaneous evolution of modularity and network motifs. Proc Natl Acad Sci USA 102:13773-13778. CrossRef Medline

Kashtan N, Noor E, Alon U (2007) Varying environments can speed up evolution. Proc Natl Acad Sci USA 104:13711-13716. CrossRef

Kitzbichler MG, Henson RN, Smith ML, Nathan PJ, Bullmore ET (2011) Cognitive effort drives workspace configuration of human brain functional networks. J Neurosci 31:8259-8270. CrossRef Medline

Kleerekooper I, van Rooij SJ, van den Wildenberg WP, de Leeuw M, Kahn RS, Vink M (2016) The effect of aging on fronto-striatal reactive and proactive inhibitory control. Neuroimage 132:51-58. CrossRef Medline

Konishi M, McLaren DG, Engen H, Smallwood J (2015) Shaped by the past: the default mode network supports cognition that is independent of immediate perceptual input. PLoS One 10:e132209. CrossRef Medline

Krawczyk DC, Gazzaley A, D’Esposito M (2007) Reward modulation of prefrontal and visual association cortex during an incentive working memory task. Brain Res 1141:168-177. CrossRef Medline

Lancichinetti A, Fortunato S (2012) Consensus clustering in complex networks. Sci Rep 2:336. CrossRef Medline

Leitão J, Thielscher A, Tünnerhoff J, Noppeney U (2015) Concurrent TMSfMRI reveals interactions between dorsal and ventral attentional systems. J Neurosci 35:11445-11457. CrossRef Medline

Liang X, Zebrowitz LA, Zhang Y (2010) Neural activation in the reward circuit shows a nonlinear response to facial attractiveness. Soc Neurosci 5:320-334. CrossRef Medline

Li Y, Liu Y, Li J, Qin W, Li K, Yu C, Jiang T (2009) Brain anatomical network and intelligence. PLoS Comput Biol 5:e1000395. CrossRef Medline

Linden DEJ, Prvulovic D, Formisano E, Völlinger M, Zanella FE, Goebel R, Dierks T (1999) The functional neuroanatomy of target detection: an fMRI study of visual and auditory oddball tasks. Cerebral Cortex 9:815823. CrossRef Medline

Marusak HA, Calhoun VD, Brown S, Crespo LM, Sala-Hamrick K, Gotlib IH,
Thomason ME (2017) Dynamic functional connectivity of neurocognitive networks in children. Hum Brain Mapp 38:97-108. CrossRef Medline

Mennes M, Kelly C, Colcombe S, Castellanos FX, Milham MP (2013) The extrinsic and intrinsic functional architectures of the human brain are not equivalent. Cereb Cortex 23:223-229. CrossRef Medline

Miyake A, Friedman NP (2012) The nature and organization of individual differences in executive functions: four general conclusions. Curr Dir Psychol Sci 21:8-14. CrossRef Medline

Moussa MN, Vechlekar CD, Burdette JH, Steen MR, Hugenschmidt CE, Laurienti PJ (2011) Changes in cognitive state alter human functional brain networks. Front Hum Neurosci 5:83. CrossRef Medline

Mucha PJ, Richardson T, Macon K, Porter MA, Onnela JP (2010) Community structure in time-dependent, multiscale, and multiplex networks. Science 328:876-878. CrossRef Medline

Nigg JT, Wong MM, Martel MM, Jester JM, Puttler LI, Glass JM (2006) Poor response inhibition as a predictor of problem drinking and illicit drug use in adolescents at risk for alcoholism and other substance use disorders. J Acad Child Adolesc Psychiatry 45:468-475. CrossRef Medline

Ofen N, Chai XJ, Schuil KD, Whitfield-Gabrieli S, Gabrieli JD (2012) The development of brain systems associated with successful memory retrieval of scenes. J Neurosci 32:10012-10020. CrossRef Medline

Paschke LM, Walter H, Steimke R, Ludwig VU, Gaschler R, Schubert T, Stelzel C (2015) Motivation by potential gains and losses affects control processes via different mechanisms in the attentional network. Neuroimage 111:549-561. CrossRef Medline

Piguet C, Cojan Y, Sterpenich V, Desseilles M, Bertschy G, Vuilleumier P (2016) Alterations in neural systems mediating cognitive flexibility and inhibition in mood disorders. Hum Brain Mapp 37:1335-1348. CrossRef Medline

Power JD, Barnes KA, Snyder AZ, Schlaggar BL, Petersen SE (2012) Spurious but systematic correlations in functional connectivity MRI networks arise from subject motion. Neuroimage 59:2142-2154. CrossRef Medline

Power JD, Schlaggar BL, Petersen SE (2015) Recent progress and outstanding issues in motion correction in resting state fMRI. Neuroimage 105: 536-551. CrossRef Medline

Power JD, Cohen AL, Nelson SM, Wig GS, Barnes KA, Church JA, Vogel AC, Laumann TO, Miezin FM, Schlaggar BL,Petersen SE (2011) Functional network organization of the human brain. Neuron 72:665-678. CrossRef Medline

Preacher KJ, Curran PJ, Bauer DJ (2006) Computational tools for probing interaction effects in multiple linear regression, multilevel modeling, and latent curve analysis. J Educ Behav Stat 31:437-448. CrossRef

Raudenbush SW, Bryk AS (2002) Hierarchical linear models (Ed 2). Thousand Oaks, CA: Sage.

Raudenbush S, Bryk AS, Cheong YF, Congdon R, du Toit M (2013) HLM 7: Hierarchical linear and nonlinear modeling. Chicago: Scientific Software International.

Rissman J, Gazzaley A, D’Esposito M (2009) The effect of non-visual working memory load on top-down modulation of visual processing. Neuropsychologia 47:1637-1646. CrossRef Medline

Rubinov M, Sporns O (2010) Complex network measures of brain connectivity: uses and interpretations. Neuroimage 52:1059-1069. CrossRef Medline

Rubinov M, Sporns O (2011) Weight-conserving characterization of complex functional brain networks. Neuroimage 56:2068-2079. CrossRef Medline

Sadaghiani S, D’Esposito M (2015) Functional characterization of the cingulo-opercular network in the maintenance of tonic alertness. Cereb Cortex 25:2763-2773. CrossRef Medline

Satterthwaite TD, Wolf DH, Ruparel K, Erus G, Elliott MA, Eickhoff SB, Gennatas ED, Jackson C, Prabhakaran K, Smith A, Hakonarson H, Verma R, Davatzikos C, Gur RE, Gur RC (2013) Heterogeneous impact of motion on fundamental patterns of developmental changes in functional connectivity during youth. Neuroimage 83:45-57. CrossRef Medline

Satterthwaite TD, Wolf DH, Roalf DR, Ruparel K, Erus G, Vandekar S, Gennatas ED, Elliott MA, Smith A, Hakonarson H, Verma R, Davatzikos C, Gur RE, Gur RC (2015) Linked sex differences in cognition and functional connectivity in youth. Cereb Cortex 25:2383-2394. CrossRef Medline

Scheinost D, Finn ES, Tokoglu F, Shen X, Papademetris X, Hampson M, Constable RT (2015) Sex differences in normal age trajectories of 
functional brain networks. Hum Brain Mapp 36:1524-1535. CrossRef Medline

Seeley WW, Menon V, Schatzberg AF, Keller J, Glover GH, Kenna H, Reiss AL, Greicius MD (2007) Dissociable intrinsic connectivity networks for salience processing and executive control. J Neurosci 27:2349-2356. CrossRef Medline

Sestieri C, Corbetta M, Spadone S, Romani GL, Shulman GL (2014) Domain-general signals in the cingulo-opercular network for visuospatial attention and episodic memory. J Cogn Neurosci 26:551-568. CrossRef Medline

Sherry A, Henson RK (2005) Conducting and interpreting canonical correlation analysis in personality research: a user-friendly primer. J Pers Assess 84:37-48. CrossRef Medline

Shirer WR, Ryali S, Rykhlevskaia E, Menon V, Greicius MD (2012) Decoding subject-driven cognitive states with whole-brain connectivity patterns. Cereb Cortex 22:158-165. CrossRef Medline

Smith DV, Sip KE, Delgado MR (2015) Functional connectivity with distinct neural networks tracks fluctuations in gain/loss framing susceptibility. Hum Brain Mapp 36:2743-2755. CrossRef Medline

Smith SM, Jenkinson M, Woolrich MW, Beckmann CF, Behrens TE, Matthews PM (2004) Advances in functional and structural MR image analysis and implementation as FSL. Neuroimage 23:208-219. CrossRef Medline

Smith SM, Beckmann CF, Andersson J, Auerbach EJ, Bijsterbosch J, Douaud G, Duff E, Feinberg DA, Griffanti L, Harms MP, Kelly M, Laumann T, Miller KL, Moeller S, Petersen S, Power J, Salimi-Khorshidi G, Snyder AZ, Vu AT, Woolrich MW, et al. (2013) Resting-state fMRI in the Human Connectome Project. Neuroimage 80:144-168. Medline

Smith SM, Nichols TE, Vidaurre D, Winkler AM, Behrens TE, Glasser MF, Ugurbil K, Barch DM, Van Essen DC, Miller KL (2015) A positivenegative mode of population covariation links brain connectivity, demographics and behavior. Nat Neurosci 18:1565-1567. CrossRef Medline

Sporns O, Betzel RF (2016) Modular brain networks. Annu Rev Psychol 67:613-640. CrossRef Medline

Spreng RN, Stevens WD, Chamberlain JP, Gilmore AW, Schacter DL (2010) Default network activity, coupled with the frontoparietal control network, supports goal-directed cognition. Neuroimage 53:303-317. CrossRef Medline

Spreng RN, DuPre E, Selarka D, Garcia J, Gojkovic S, Mildner J, Luh WM, Turner GR (2014) Goal-congruent default network activity facilitates EF. J Neurosci 34:14108-14114. CrossRef Medline

Spreng RN, Andrews-Hanna JR (2015) The default network and social cognition. In: Brain mapping: an encyclopedic reference (Toga AW, ed), pp 165-169. Cambridge, MA: Academic Elsevier.

Sridharan D, Levitin DJ, Menon V (2008) A critical role for the right frontoinsular cortex in switching between central-executive and default-mode networks. Proc Natl Acad Sci USA105:12569-12574. CrossRef Medline

Stephanou K, Davey CG, Kerestes R, Whittle S, Pujol J, Yücel M, Fornito A, López-Solà M, Harrison BJ (2016) Brain functional correlates of emotion regulation across adolescence and young adulthood. Hum Brain Mapp 37:7-19. CrossRef Medline
Toga AW, Thompson PM, Sowell ER (2006) Mapping brain maturation. Trends Neurosci 29:148-159. CrossRef Medline

Traag VA, Bruggeman J (2009) Community detection in networks with positive and negative links. Physical Review E 80:036115. CrossRef Medline

Tsvetanov KA, Henson RN, Tyler LK, Razi A, Geerligs L, Ham TE, Rowe JB (2016) Extrinsic and intrinsic brain network connectivity maintains cognition across the lifespan despite accelerated decay of regional brain activation. J Neurosci 36:3115-3126. CrossRef Medline

van den Heuvel MP, Stam CJ, Kahn RS, Hulshoff Pol HE (2009) Efficiency of functional brain networks and intellectual performance. J Neurosci 29:7619-7624. CrossRef Medline

Van Dijk KR, Sabuncu MR, Buckner RL (2012) The influence of head motion on intrinsic functional connectivity MRI. Neuroimage 59:431-438. CrossRef Medline

Van Essen DC, Ugurbil K, Auerbach E, Barch D, Behrens TE, Bucholz R, Chang A, Chen L, Corbetta M, Curtiss SW, Della Penna S, Feinberg D, Glasser MF, Harel N, Heath AC, Larson-Prior L, Marcus D, Michalareas G, Moeller S, Oostenveld R, et al. (2012) The Human Connectome Project: a data acquisition perspective. Neuroimage 62:2222-2231. CrossRef Medline

van Duijvenvoorde AC, Achterberg M, Braams BR, Peters S, Crone EA (2016) Testing a dual-systems model of adolescent brain development using resting-state connectivity analyses. Neuroimage 124:409-420. CrossRef Medline

Vatansever D, Menon DK, Manktelow AE, Sahakian BJ, Stamatakis EA (2015) Default mode dynamics for global functional integration. J Neurosci 35:15254-15262. CrossRef Medline

Veroude K, Jolles J, Croiset G, Krabbendam L (2013) Changes in neural mechanisms of cognitive control during the transition from late adolescence to young adulthood. Dev Cogn Neurosci 5:63-70. CrossRef Medline

Vink M, Zandbelt BB, Gladwin T, Hillegers M, Hoogendam JM, den Wildenberg WP, Du Plessis S, Kahn RS (2014) Frontostriatal activity and connectivity increase during proactive inhibition across adolescence and early adulthood. Hum Brain Mapp 35:4415-4427. CrossRef Medline

Watanabe M (2007) Role of anticipated reward in cognitive behavioral control. Curr Opin Neurobiol 17:213-219. CrossRef Medline

Wheatley T, Milleville SC, Martin A (2007) Understanding animate agents: distinct roles for the social network and mirror system. Psychol Sci 18: 469-474. CrossRef Medline

Whitfield-Gabrieli S, Nieto-Castanon A (2012) CONN: a functional connectivity toolbox for correlated and anticorrelated brain networks. Brain Connect 2:125-141. CrossRef Medline

Wig GS, Schlaggar BL, Petersen SE (2011) Concepts and principles in the analysis of brain networks. Ann N Y Acad Sci 1224:126-146. CrossRef Medline

Xia M, Wang J, He Y (2013) BrainNet Viewer: a network visualization tool for human brain connectomics. PLoS One 8:e68910. CrossRef Medline

Zalesky A, Fornito A, Cocchi L, Gollo LL, Breakspear M (2014) Timeresolved resting-state brain networks. Proc Natl Acad Sci U S A 111: 10341-10346. CrossRef Medline 